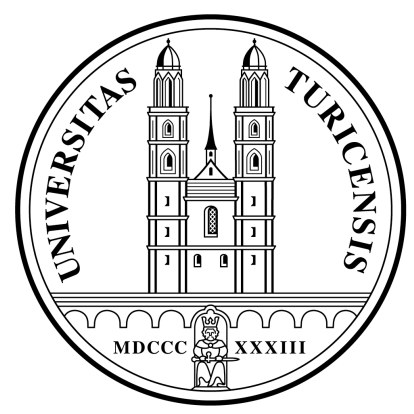

Institute for Empirical Research in Economics

University of Zurich

Working Paper Series

ISSN 1424-0459

Working Paper No. 154

Friedman Meets Hosios: Efficiency in Search Models of Money

Aleksander Berentsen, Guillaume Rocheteau and Shouyong Shi

June 2003 


\title{
Friedman Meets Hosios: Efficiency in Search Models of Money*
}

\author{
Aleksander Berentsen \\ University of Basel, Switzerland \\ Guillaume Rocheteau \\ Australian National University, Australia \\ Shouyong Shi \\ University of Toronto, Canada
}

2002

\begin{abstract}
In this paper we study the inefficiencies of the monetary equilibrium and optimal monetary policies in a search economy. We show that the same frictions that give fiat money a positive value generate an inefficient quantity of goods in each trade and an inefficient number of trades (or search decisions). The Friedman rule eliminates the first inefficiency and the Hosios rule the second. A monetary equilibrium attains the social optimum if and only if both rules are satisfied. When the two rules cannot be satisfied simultaneously, which occurs in a large set of economies, optimal monetary policy achieves only the second best. We analyze when the second-best monetary policy exceeds the Friedman rule and when it obeys the Friedman rule. Furthermore, we extend the analysis to an economy with barter and show how the Hosios rule must be modified in order to internalize all search externalities.
\end{abstract}

Keywords : Money, Search, Friedman rule, Hosios rule.

\footnotetext{
*Aleksander Berentsen: University of Basel, Economics Department (WWZ), Petersgraben 51, Postfach, 4003 Basel, Switzerland (email: aleksander.berentsen@unibas.ch). Guillaume Rocheteau: Copland Building, School of Economics, Australian National University, Canberra ACT 0200, Australia (email: guillaume.rocheteau@anu.edu.au). Shouyong Shi: Department of Economics, University of Toronto, 150 St. George Street, Toronto, Ontario, Canada, M5S 3G7 (email: shouyong@economics.utoronto.ca). This paper has been presented at Canadian Macroeconomic Study Group meeting (Vancouver, 2001), the Conference on Monetary Economics at the Federal Reserve Bank of Cleveland (2001), Australian National University (2001), and the Society for Economic Dynamics meeting (New York, 2002). We have received useful comments from the participants of these conferences and workshops. We are especially grateful to Ricardo Lagos, Matthew Ryan, and Randall Wright for their comments. Shi would like to acknowledge the Social Sciences and Humanities Research Council of Canada for financial support. All remaining errors are ours alone.
} 


\section{Introduction}

In this paper we study the inefficiencies of the monetary equilibrium and optimal monetary policies in a search economy. The same frictions that give fiat money a positive value generate two inefficiencies in the monetary equilibrium. To eliminate these inefficiencies, the equilibrium must satisfy both the Friedman rule (1969) and the Hosios (1990) rule. These two rules give conflicting descriptions for optimal monetary policy. We show when optimal money growth obeys the Friedman rule and when it exceeds the Friedman rule.

All well-specified monetary models use frictions in the goods market to support positively valued fiat money. In search monetary models pioneered by Kiyotaki and Wright (1991, 1993), the frictions are decentralized exchanges, as modelled by random bilateral matching, and private trading histories (see Kocherlakota 1998). These frictions make it difficult for agents to execute all socially desirable trades. Money facilitates exchange and improves social welfare by enabling agents to trade more efficiently than barter in matches where the two agents have only single coincidence of wants. ${ }^{1}$ The monetary equilibrium in such an economy exhibits two types of inefficiency. One is that the quantity of goods in each trade is inefficient, because the buyer in the match is constrained by the real money balance. The other is that the number of trades is inefficient, because agents ignore the externalities that their search decisions create on other agents' matching probabilities.

Standard monetary models possess the first type of inefficiency but not the second. In those models, markets are assumed to be Walrasian and so the number of trades is immaterial, provided that prices clear the markets. As a result, monetary policy can restore efficiency by following the Friedman rule, the simplest form of which requires the money stock to contract at the discount rate. $^{2}$ The Friedman rule maximizes the real value of money, thus making the money constraint non-binding and inducing the efficient quantity of trade. When exchanges are decentralized, however, the Friedman rule may fail to restore efficiency because it may fail to correct the inefficient number of trades generated by search externalities.

The Hosios rule describes how a market can internalize search externalities. First proposed by Mortensen (1982) and then shown more generally by Hosios (1990), this rule requires that the match surplus in a trade be divided between the two agents to properly compensate their search decisions. More precisely, buyers' (or sellers') share of the match surplus should be equal

\footnotetext{
${ }^{1}$ More generally, money facilitates exchanges in asymmetric matches, those in which the two agents have either asymmetric bargaining powers or asymmetric demands for each other's goods. The lack of double coincidence of wants is an extreme form of asymmetric demands, but not a necessary condition for money to be valued and welfare-improving in a search model. See Engineer and Shi $(1998,2001)$ and Berentsen and Rocheteau (2003).

${ }^{2}$ Woodford (1990) describes a variety of ways to state the Friedman rule and surveys the literature of traditional monetary models along this line. For convenience, we interpret the Friedman rule as a requirement on the contraction rate of the money stock, because our model focuses on the effects of money growth. Some other interpretations of the Friedman rule, such as a zero net nominal interest rate, are also valid in our model.
} 
to these agents' share of contribution to the total number of trades. The Hosios rule is well established in the labor search literature pioneered by Diamond (1982), Mortensen (1982) and Pissarides (1990). However, it is a stringent requirement and seemingly unrelated to monetary policy. In most search models, the surplus shares and the matching shares are both exogenous parameters determined, respectively, by the Nash bargaining formula and a matching function. Such economies satisfy the Hosios rule only if one assumes that the two unrelated parameters are equal to each other, with which monetary policy has nothing to do.

Our model provides an intimate link between the Hosios rule and monetary policy. Crucial to this link is the result, emphasized first by Shi (2001a), that the surplus division in a monetary trade is endogenous when the trade is constrained by the buyer's real money balance. This constraint allows the buyer to credibly limit his offer in bargaining, thus extracting a larger share than if there is no such constraint. The extent to which the buyer can increase his surplus share is determined by how severely the trade is constrained by the real money balance, and hence by monetary policy. When money growth obeys the Friedman rule, the money constraint does not bind and so the buyer's surplus share reaches a constant lower bound $\theta \in(0,1)$, which coincides with the exogenous surplus share in the Nash bargaining formula. An increase in the money growth rate, by reducing the real value of money, makes the money constraint more binding and hence increases the buyer's surplus share, although it also reduces the total surplus in the trade. Through this effect on the surplus division, monetary policy can help the equilibrium satisfy the Hosios rule.

The Friedman rule and the Hosios rule exert different pressures on optimal monetary policy. The Friedman rule maximizes the real money balance, and so it induces an efficient quantity of goods in each trade, or equivalently, an efficient size of the match surplus. However, it does not necessarily induce a division of the surplus that is required for search decisions to be efficient. On the other hand, monetary policy under the Hosios rule induces an efficient division of the surplus but it does not necessarily generate an efficient size of the surplus. The two rules coincide with each other if and only if buyers' share in the matching function under the Friedman rule, denoted $\eta^{*}$, is equal to buyers' surplus share in unconstrained bargaining (i.e., $\theta$ ). In this case, the Friedman rule achieves the social optimum. In all other economies, optimal monetary policy achieves the second best.

The second-best monetary policy depends on whether $\theta<\eta^{*}$. If $\theta<\eta^{*}$, the Hosios rule requires the money growth rate to exceed the Friedman rule. In this case, the equilibrium under the Friedman rule generates inefficient search decisions, because buyers get a surplus share less than their share of contribution to matches, while the equilibrium under the Hosios rule generates an inefficiently low quantity of goods in each trade. To make the best compromise between the efficient size and the efficient division of the match surplus, the optimal money growth rate exceeds the Friedman rule and is lower than what the Hosios rule requires. If $\theta>\eta^{*}$, the Hosios 
rule requires the money growth rate to be lower than the Friedman rule, which is infeasible in the monetary equilibrium. In this case, the Friedman rule is optimal, as it achieves the efficient quantity of goods in each trade and brings search decisions closer to the efficient ones than does any other feasible money growth rate.

We extend these results to an economy where barter and monetary trades both exist. In such an economy, the original Hosios rule fails to internalize all search externalities, because it does not incorporate search externalities between the two types of trades. In particular, monetary trades crowd out barter trades. The Hosios rule in its original form does not incorporate this negative externality and as a result, it compensates money holders exceedingly and producers deficiently. To internalize all search externalities, we propose a measure of the effective number of trade matches. This allows us to modify the Hosios rule in an intuitive way and to adapt the above efficiency results to the economy with barter.

The papers closest to ours are $\operatorname{Li}(1995,1997)$ and Shi $(1997,2001 \mathrm{a})$. Using a search model with indivisible money and indivisible goods, Li provides important insights into how monetary policy can induce efficient search decisions. However, the assumption of indivisible money makes the model incapable of examining the effects of money growth or associating the Friedman rule with money growth. ${ }^{3}$ Also, because goods are indivisible in Li's model, there is no inefficiency in the quantity of goods in each trade, thus precluding the trade-off between this efficiency in the intensive margin of trade and the efficiency in the extensive margin. To analyze efficiency adequately, we adopt the search model with divisible money and divisible goods, developed in a series of papers by Shi. Some results in this paper have their precursors in Shi (1997). For example, the Friedman rule is optimal when search intensities are exogenous and endogenous search decisions can push the optimal money growth rate above the Friedman rule. ${ }^{4}$

Our paper makes two main contributions. First, we study the inefficiencies in monetary search models systematically. By adopting a general matching function, we are able to attribute inefficient search decisions formally to the violation of the Hosios rule. This allows us to characterize optimal monetary policies generally as a compromise between the Friedman rule and the Hosios rule. ${ }^{5}$ Because the Hosios rule is well known in the labor search literature, our analysis also serves as an interesting link between the monetary search literature and the labor search literature. Second, we modify the Hosios rule to incorporate barter trades. This modification is an important

\footnotetext{
${ }^{3}$ To examine the Friedman rule in a model with indivisible money, one must allow the government to pay interest in terms of consumption goods to money holdings. When such an interest payment gives money a rate of return equal to the discount rate, the Friedman rule is satisfied. However, this version of the Friedman rule has nothing to do with money growth and, because of the interest payment, money is not strictly fiat.

${ }^{4}$ Some other authors have also examined the Friedman rule using variations of Shi's divisible-money models. For example, Berentsen and Rocheteau (2003) emphasize the inefficiency of barter when there is asymmetric demand in matches, and Faig (2001) emphasizes the relationship between the production sector and the commerce sector.

${ }^{5}$ We examine the search externalities both through the choice of the fraction of buyers as in Shi $(1997,1999 \mathrm{a})$ and through the search intensity as in Li $(1995,1997)$.
} 
contribution to the search literature, because the method is generally useful for characterizing efficient search decisions with heterogeneous types of trades.

A majority of money search models assume either indivisible money (e.g., Shi 1995 and Trejos and Wright 1995), or indivisible goods (e.g., Green and Zhou 1998), or both (e.g., Kiyotaki and Wright 1991, 1993). These are not just technical assumptions (Berentsen and Rocheteau 2002). In particular, models with indivisible money are incapable of analyzing money growth and unnecessarily tie the fraction of money holders in the economy to the money stock. As a result, many previous models mistake an optimal fraction of money holders for an optimum quantity of money. We will illustrate this mistake in section 5.4.

Most analyses of the Friedman rule employ standard monetary models that assume centralized exchanges such as Walrasian markets (see Woodford 1990 for a survey). We choose a search model instead, for two reasons. First, search models clearly specify the physical environment in which fiat money can be positively valued in equilibrium, and so the welfare analysis is internally consistent. $^{6}$ Second, the very frictions that support positively valued fiat money in the search model generate the two inefficiencies of trades in our model and cause the Friedman rule to be sub-optimal in some cases. In contrast, traditional analyses make the Friedman rule sub-optimal by introducing additional elements, such as distortionary taxes (Chamley 1985 and Chari, et al. 1991) and monopolistic competition (Schmitt-Grohe and Uribe 2000). These distortions are realistic, but they are not necessary for supporting positively valued money. As a result, the suboptimality of the Friedman rule in those models is not robust, in the sense that other policies such as fiscal policies are the best policies to eliminate the distortions. The same corrective prescription does not work in our model without eliminating the role of money (see more discussions in the conclusion).

The Friedman rule can also be sub-optimal in economies where there is a need to redistribute liquidity between different types of agents. One such model is the Bewley (1980) model, where agents face income risks and there is no market to contract over future income. If some agents' consumption levels are forced into a corner solution in certain states of nature, an expansionary monetary policy can increase welfare by providing liquidity to such agents (see Levine 1991 and Woodford 1990). Molico (1997) and Deviatov and Wallace (2001) make a similar argument in search models of indivisible money, where the random-matching shocks generate a distribution of money holdings across agents and force some agents' consumption to be inefficiently low. We eliminate this inefficiency by making the distribution of money holdings degenerate across households, in order to focus on the inefficiency of search decisions. Other related models are variations of the Townsend (1980) model (e.g., Shi 1996b) or Williamson (1996), where spatial or sequential separation of markets can create the need for redistribution. Our model also creates

\footnotetext{
${ }^{6}$ See Wallace (2001) for the arguments why traditional monetary models are not suitable for analyzing the role of money in improving welfare.
} 
market separation, through bilateral matching. However, the fundamental source of the suboptimality of the Friedman rule in our model, i.e., the inefficient number of trades, is a nonWalrasian feature that does not exist in these Walrasian models.

\section{Households and Matching}

The environment is similar to that of Shi (1999a, 2001a), except for the addition of the choice of search intensities and the use of a more general matching function.

\subsection{Households}

Time is discrete. The economy consists of $H$ types of infinitely-lived households where $H$ is a large number. Each type consists of a large number of households, normalized to size one. Use lower-case letters to denote a particular household's variables and capital-case letters other households' variables or aggregate variables.

A household $h$ is specialized in both production and consumption. Until section 6 , we assume that preferences and technologies are such that barter trades cannot occur. So, for the moment, all trades involve the use of an intrinsically useless, perfectly divisible and storable object called money. Goods are perfectly divisible and perishable. The utility of consuming $q$ units of consumption goods is $u(q)$ and the disutility of producing $q$ units of goods is $c(q)$. For simplicity, let $u(q)=u^{\prime} q$, where $u^{\prime}>0$ is a constant, so that the cost is measured in utility. The cost function satisfies $c(0)=0, c^{\prime}(q)>0, c^{\prime}(0)=0$, and $c^{\prime \prime}(q)>0$. We assume that there exists $q^{*} \in(0, \infty)$ such that $c^{\prime}\left(q^{*}\right)=u^{\prime}$.

Each household consists of a large number of members who carry out different tasks but regard the household's utility as the common objective. ${ }^{7}$ The size of the members in each household is normalized to one. There are two types of members in each household, buyers and sellers. Buyers use money to purchase the household's consumption goods and sellers produce. For the moment, we fix the composition of buyers and sellers, with a fraction $n$ of the members being buyers and a fraction $1-n$ sellers, where $0<n<1$ (we endogenize $n$ in section 5.4). Each buyer carries $m_{t} / n$ units of money into the market, where $m_{t}$ is the household's total money holdings before the market opens in period $t$. Before the members go to the market, the household chooses the search intensity $\sigma_{b}$ for each buyer and $\sigma_{s}$ for each seller. The disutility of search intensities is

\footnotetext{
${ }^{7}$ The large household assumption, extending a similar one in Lucas (1990), makes the distribution of money holdings degenerate across households and so allows for a tractable analysis of money growth and inflation, see Shi (1997, 1998, 1999a, 2001a), Head and Shi (2000), and Berentsen and Rocheteau (2001, 2002, 2003). Lagos and Wright (2002) adopt a different assumption to make the money distribution degenerate. They assume that, after the random-matching market closes in each period, a Walrasian market opens in which agents can trade a homogeneous good whose utility and cost functions are both linear. This achieves the same purpose as risk-sharing in our large household and generates the same analytical results.
} 
$\phi(\sigma)$ and, to ease exposition, we specify $\phi(\sigma)=\phi_{0}\left(\sigma^{\alpha}-1\right)$, where $\phi_{0}>0$ and $\alpha>1$.

The household also prescribes the trading strategies to the members to carry out in matches, which will be described later in a sequential bargaining game. Since goods and money are perfectly divisible, agents can exchange any quantity of money and goods as they wish, provided that the traded quantity of money does not exceed what the buyer in the match has.

After trading, the household pools the consumption goods purchased by the buyers and evenly distributes them to the members for consumption. The household also pools the money balance acquired in trade or left over from trade, to be allocated to buyers in the next period. Before proceeding to the next period, the household receives a lump-sum transfer of money $L_{t}=(\gamma-$ 1) $M_{t}$, where $M_{t}$ is the money holding per household in period $t$ and $\gamma$ is a constant gross rate of growth of $M$.

\subsection{Matching function}

Agents are matched randomly and bilaterally in the market. We are interested in the matches where a trade can occur, i.e., where the seller can produce the buyer's consumption goods. Call such a match a trade match. Let $B=H N$ be the total number of buyers in the economy and $S=H(1-N)$ the number of sellers, where $N=n$ is the number (and the fraction) of buyers per household (the distinction between $N$ and $n$ is meaningful only when $n$ is endogenous). Let $\Sigma_{b}$ be the average search intensity of buyers and $\Sigma_{s}$ of sellers. The aggregate search intensity of buyers is $B \Sigma_{b}$ and of sellers $S \Sigma_{s}$. We sometimes refer to these search intensities as search units.

The total number of trade matches in a period is given by a matching function, $\mathcal{M}\left(B \Sigma_{b}, S \Sigma_{s}\right)$. As is common in the labor search literature (e.g., Diamond 1982, Mortensen 1982, and Pissarides 1990), the matching function is strictly increasing and concave in the two arguments, and is linearly homogeneous. Define the tightness of the market by

$$
T \equiv S \Sigma_{s} /\left(B \Sigma_{b}\right)=(1-N) \Sigma_{s} /\left(N \Sigma_{b}\right)
$$

If $T$ is high, the market is thick for buyers and thin for sellers.

An important characteristic of the matching function is the marginal contributions of each side of the market to the number of trade matches, defined below:

$$
K_{b}(T) \equiv \frac{\partial \mathcal{M}\left(B \Sigma_{b}, S \Sigma_{s}\right)}{\partial\left(B \Sigma_{b}\right)}, \quad K_{s}(T) \equiv \frac{\partial \mathcal{M}\left(B \Sigma_{b}, S \Sigma_{s}\right)}{\partial\left(S \Sigma_{s}\right)} .
$$

Because the matching function is linearly homogeneous, the total number of trade matches is the sum of the two sides' contributions, i.e., $\mathcal{M}\left(B \Sigma_{b}, S \Sigma_{s}\right)=K_{b} B \Sigma_{b}+K_{s} S \Sigma_{s}$. The share of buyers' contribution to trade matches is defined as

$$
\eta(T) \equiv K_{b} B \Sigma_{b} / \mathcal{M}
$$

Clearly, the share of sellers' contribution is $1-\eta$, and $\eta \in[0,1]$. 
We can also calculate the average matching rate per search intensity for buyers and sellers, respectively, as follows:

$$
\begin{aligned}
& A_{b}(T) \equiv \mathcal{M}\left(B \Sigma_{b}, S \Sigma_{s}\right) /\left(B \Sigma_{b}\right)=\mathcal{M}(1, T) \\
& A_{s}(T) \equiv \mathcal{M}\left(B \Sigma_{b}, S \Sigma_{s}\right) /\left(S \Sigma_{s}\right)=\mathcal{M}(1, T) / T .
\end{aligned}
$$

We have $A_{b}(T)=T A_{s}(T), A_{b}^{\prime}(T)>0, A_{b}^{\prime \prime}(T)<0, A_{s}^{\prime}(T)<0$ and $A_{s}^{\prime \prime}(T)>0$. Moreover, the matching rates $\left(A_{b}, A_{s}\right)$ and the marginal contributions $\left(K_{b}, K_{s}\right)$ are related to each other as follows:

$$
\begin{aligned}
K_{b}(T) & =\eta(T) A_{b}(T), \quad K_{s}(T)=[1-\eta(T)] A_{s}(T), \\
\eta(T) & =1-T A_{b}^{\prime}(T) / A_{b}(T)=-T A_{s}^{\prime}(T) / A_{s}(T) .
\end{aligned}
$$

Because of the last relationship, we also call $\eta(T)$ the elasticity of the matching rate $A_{s}(T)$.

Individual households take aggregate search intensities and aggregate numbers of buyers and sellers as given. So, they take the tightness $T$ and the rates $\left(A_{b}, A_{s}\right)$ as given. Note that $A_{b}$ and $A_{s}$ are the average matching rates per search intensity, not the matching rates per person. The latter can be influenced by individual households' choices of search intensity. For a household that chooses search intensity $\sigma_{b}$ for its buyers and $\sigma_{s}$ for its sellers, each buyer has a trade match with probability $\sigma_{b} A_{b}(T)$ and each seller with probability $\sigma_{s} A_{s}(T) .{ }^{8}$

Two special cases of the above matching function are worth noting. One is as follows:

$$
\mathcal{M}\left(B \Sigma_{b}, S \Sigma_{s}\right)=\frac{z\left(B \Sigma_{b}\right)\left(S \Sigma_{s}\right)}{B \Sigma_{b}+S \Sigma_{s}}=\frac{z\left(N \Sigma_{b}\right)(1-N) \Sigma_{s}}{N \Sigma_{b}+(1-N) \Sigma_{s}}
$$

where $z>0$ is a constant. This specification implies $\eta(T)=T /(1+T), A_{b}(T)=z T /(1+T)$ and $A_{s}(T)=z /(1+T)$. Since $A_{b}(T)+A_{s}(T)=z$, we call the above matching technology the additive-matching-rate technology. This matching function encompasses the matching technology used in most monetary search models as a special case. In the latter models, the number of trade matches (in the absence of barter) is $z N(1-N)$, which can be obtained from (6) by setting $\Sigma_{b}=\Sigma_{s}$ and $z$ to the probability of a single coincidence of wants between two randomly selected agents.

The second special case of the matching function is the Cobb-Douglas function:

$$
\mathcal{M}\left(B \Sigma_{b}, S \Sigma_{s}\right)=z\left(B \Sigma_{b}\right)^{\eta}\left(S \Sigma_{s}\right)^{1-\eta}, \quad 0<\eta<1 .
$$

This specification implies $\eta(T)=\eta, A_{b}(T)=z T^{1-\eta}$ and $A_{s}(T)=z T^{-\eta}$. The Cobb-Douglas matching function has been frequently used in labor search models and, recently, in monetary search models (Li 1997, Shi 1998 and Head and Shi 2000).

\footnotetext{
${ }^{8}$ We assume $\mathcal{M}\left(B \Sigma_{b}, S \Sigma_{s}\right)<\min (B, S)$ so that $\sigma_{b} A_{b}<\sigma_{b} / \Sigma_{b}$ and $\sigma_{s} A_{s}<\sigma_{s} / \Sigma_{s}$. Thus, individual agents' matching rates are indeed probabilities in or near symmetric equilibria.
} 
The main difference between the two special cases is that the share $\eta$ is a constant in the Cobb-Douglas function but a function of $T$ in the additive-matching-rate function. In general, $\eta$ can be increasing, decreasing or independent of $T$. An example of $\eta^{\prime}(T)<0$ is the CES matching function where the elasticity of substitution between the two factors is less than 1. For various proofs of existence, we restrict the extent to which $\eta(T)$ decreases with $T$ if $\eta^{\prime}(T)<0$. Precisely, denote

$$
f(T)=\frac{1}{T}\left(\frac{1}{\eta(T)}-1\right) .
$$

We assume $f^{\prime}(T)<0, f(0)>0$ and $f(\infty)<\infty$. These technical assumptions are satisfied by all examples we mentioned so far, including the CES matching technology.

\subsection{Search externalities and the Hosios rule}

Each household takes the matching rates $\left(A_{b}, A_{s}\right)$ as given and ignores the influence of its search decisions on other households' matching rates. This ignorance creates two types of externalities, as is well known in the labor search literature. To see these externalities, consider a household that increases its buyers' search intensity marginally. This decision makes the market marginally thicker for sellers than before and thinner for buyers. That is, the matching probability of other households' sellers increases, which is a positive externality, but the matching probability of buyers decreases, which is a negative externality. Similarly, a seller's search decision creates two opposite externalities.

The search decisions are socially efficient only when the opposite externalities cancel each other. This is achieved if the economy satisfies the Hosios (1990) rule, which requires that agents be compensated according to their contributions to the match formation. That is, the share of the match surplus that buyers (sellers) get in trades should be equal to the share that such agents' search intensities contribute to the number of trade matches. More precisely, if $\Theta$ is a buyer's surplus share in a trade, then the Hosios rule requires: ${ }^{9}$

$$
\Theta=\eta(T)
$$

In bargaining games with transferable utility, the share $\Theta$ is usually constant and equal to the exogenous bargaining weight of buyers in the Nash bargaining solution. If the matching function is Cobb-Douglas, then $\eta$ is also constant, in which case the Hosios rule exogenously ties the two constants. If $\eta$ depends on $T$, as in the additive-matching-rate function, the Hosios rule requires $T$ to have a particular value. In contrast, our model generates an endogenous $\Theta$ that depends on monetary policy. So, monetary policy can achieve the Hosios rule even when $\eta$ is constant.

\footnotetext{
${ }^{9}$ Note that the matching function must be linearly homogeneous, which we assume, in order for the buyers' and sellers' surplus shares to be both equal to their corresponding shares of contribution to the number of trade matches.
} 


\section{Social Optimum}

We first describe the social optimum. Since all households are identical, it is natural to require the social planner to treat them equally and to describe the same allocation for each household. Like most analyses on the Friedman rule, we focus on social welfare in the steady state. The social planner chooses the search intensity for each buyer and seller, $\left(\Sigma_{b}, \Sigma_{s}\right)$, and the quantity of goods produced in each trade match, $Q$, to maximize the following steady-state utility per period of the representative household:

$$
\mathcal{W}=\mathcal{M}\left(N \Sigma_{b},(1-N) \Sigma_{s}\right)[u(Q)-c(Q)]-N \phi\left(\Sigma_{b}\right)-(1-N) \phi\left(\Sigma_{s}\right)
$$

Here, we have divided the matching function by the number of households, $H$, to obtain the number of trade matches per household, which is $\mathcal{M}\left(N \Sigma_{b},(1-N) \Sigma_{s}\right)$. The first term in the welfare function is a household's total utility of consumption net disutility of production; the remaining terms are the disutilities of search intensities. Clearly, any transfer between agents is irrelevant for social welfare.

We have the following proposition: ${ }^{10}$

Proposition 1 The social optimum is the solution to the following equations:

$$
\begin{aligned}
Q & =q^{*}, \quad \text { where } c^{\prime}\left(q^{*}\right)=u^{\prime}, \\
\phi^{\prime}\left(\Sigma_{b}\right) /[u(Q)-c(Q)] & =K_{b}(T) \quad\left(=\eta(T) A_{b}(T)\right), \\
\phi^{\prime}\left(\Sigma_{s}\right) /[u(Q)-c(Q)] & =K_{s}(T) \quad\left(=[1-\eta(T)] A_{s}(T)\right) .
\end{aligned}
$$

There exists a unique social optimum.

The social optimum requires efficiency along two dimensions, the quantity of goods in each trade, $Q$, and the total number of trade matches determined by search intensities. The quantity of goods in each trade is efficient if it equates the marginal utility of consumption and the marginal cost of production. For $i \in\{b, s\}$, the search intensity is efficient if the marginal cost of search intensity, $\phi^{\prime}\left(\Sigma_{i}\right)$, is equal to the corresponding social marginal contribution. The latter is the marginal contribution of the agent's search intensity to the number of trades, $K_{i}(T)$, times the surplus generated in each trade, $[u(Q)-c(Q)]$.

\section{Monetary Equilibrium}

We now describe a representative household's decision problem and the equilibrium.

\footnotetext{
${ }^{10}$ The proof of existence and uniqueness of the social optimum utilizes the functional form of $\phi($.$) and the$ assumptions on $f(T)$ defined in (8). Other than this, the proof is straightforward and hence omitted.
} 


\subsection{A household's decisions and bargaining}

Consider an individual household's decisions in a particular period $t$. Suppress the time subscript $t$. Shorten the subscript $t+1$ to $+1, t-1$ to -1 , and so on. An individual household takes as given the capital-case variables, i.e., other households decisions and aggregate variables. The household's decisions are the search intensities $\left(\sigma_{b}, \sigma_{s}\right)$, the money stock for the next period $m_{+1}$, and the quantities $\left(q^{b}, x^{b} ; q^{s}, x^{s}\right)$ that the household instructs the members to propose in trade matches. ${ }^{11}$ The quantity $q$ is the amount of goods that the household proposes for the seller in the match to produce and $x$ the amount of money that the buyer gives to the seller. The superscript $b$ indicates that the household's member in the match is a buyer and the superscript $s$ a seller.

The quantities $(q, x)$ are determined in sequential bargaining games with alternating offers. ${ }^{12}$ Consider a trade match between a member of the particular household in discussion and another household's member. Immediately after being matched, one of the two agents is chosen to be the first proposer. To the proposal $(q, x)$, the other agent responds by either accepting it, or rejecting it but staying in the game. If the agent accepts the offer, the bargaining game ends. The seller immediately produces $q$ units of goods for the buyer in exchange for $x$ units of money and the two agents depart from the match. If the respondent rejects the offer but stays in the game, a small interval of time $\Delta$ elapses, during which the negotiation can break down exogenously with some probability. This breakdown risk depends on whether the agent who rejects the proposal is a buyer or a seller. If a seller rejects a buyer's offer, the breakdown probability is $\theta \Delta$, where $0<\theta \leq 1$. If a buyer rejects a seller's offer, the breakdown probability is $(1-\theta) \Delta$. When the game breaks down, the two agents depart immediately and hold onto whatever they carried into the match. If the game continues after the interval $\Delta$, the two agents switch the proposing and responding roles. The game continues until an offer is accepted or there is an exogenous breakdown.

We are interested in the bargaining outcomes when the interval $\Delta$ approaches 0 . In this case, the first-mover advantage vanishes. So, we can simplify the exposition by assuming that

\footnotetext{
${ }^{11}$ If a match is not a trade match, the household instructs its member to not trade. Also, notice that we treat the relationship between a household and its members in the same way as Lucas (1990) does. That is, the members do not play strategic games with the household; rather, they simply carry out the strategies that the household makes before matching occurs. This treatment of the household is appropriate because the large household is no more than a modelling device aimed at simplifying the analysis. However, if one is interested in possible deviations by the members from the household's decisions or out-of-equilibrium considerations, see Rauch (2000) and Berentsen and Rocheteau (2001). See also our discussion in section 7.

${ }^{12}$ See Osborne and Rubinstein (1990) for a detailed treatment of sequential bargaining. A distinctive feature of the game in our paper is that bargaining is constrained by the buyer's real money balance and the value of this constraint is endogenous to the household. To clearly reveal how much each party shares the shadow cost of this money constraint, the sequential bargaining approach is superior to the axiomatic Nash bargaining approach. Similar sequential bargaining problems with money constraints have been analyzed by Shi (2001a), Head and Shi (2000), and Berentsen and Rocheteau (2001 and 2003).
} 
the members of the particular household in discussion are the first proposer in the alternatingoffer games in all trade matches that they experience. Let $v(m)$ denote the value function of a household beginning the period with a money balance $m$, where the dependence of the value function on aggregate variables is suppressed. The marginal value of money in the next period, discounted to the current period, is $\omega \equiv \beta v_{m}\left(m_{+1}\right)$ where $v_{m}$ is the derivative of $v$ with respect to $m$. Similarly, let $\Omega$ denote the discounted marginal value of money of other households.

Consider a trade match that involves a buyer from the particular household in discussion. The household instructs the buyer to propose $x^{b}$ units of money for $q^{b}$ units of goods. There are two constraints on the proposing buyer's household. First, the proposed amount of money cannot exceed the buyer's money holdings, i.e.,

$$
m / n \geq x^{b} .
$$

This constraint must be satisfied because trade is decentralized and so, during a match, each buyer is separated from other members of the household. The second constraint on the offer is that it must give the partner a surplus that is greater than or equal to the reservation surplus. This is because it is not optimal to make an offer that the partner will reject, given that the match is a trade match. The household of the partner (a seller) obtains a surplus $\Omega x^{b}-c\left(q^{b}\right)$ by accepting the offer, where $\Omega x^{b}$ is the value of the amount of money to the recipient's household and $c\left(q^{b}\right)$ is the production cost. Let $R^{s}$ denote the seller's reservation surplus. Then, the buyer's proposal must satisfy:

$$
\Omega x^{b}-c\left(q^{b}\right) \geq R^{s} .
$$

To calculate $R^{s}$, note that if the seller rejects the offer (but stays in the game), the game passes into the next round without breakdown with probability $(1-\theta \Delta)$, in which the seller proposes $\left(Q^{s}, X^{s}\right)$. Taking into account the breakdown probability, the seller's reservation surplus is

$$
R^{s}=(1-\theta \Delta)\left[\Omega X^{s}-c\left(Q^{s}\right)\right] .
$$

Similarly, in a trade match where the particular household's member is a seller, the proposal $\left(q^{s}, x^{s}\right)$ must satisfy

$$
\begin{aligned}
M / N & \geq x^{s}, \\
u\left(q^{s}\right)-\Omega x^{s} & \geq R^{b},
\end{aligned}
$$

where $M / N$ is the money holding of the partner (a buyer from another household) and $R^{b}$ is the buyer's reservation surplus given below:

$$
R^{b}=[1-(1-\theta) \Delta]\left[u\left(Q^{b}\right)-\Omega X^{b}\right] .
$$


Now we can describe the particular household's choice problem. Taking the capital-case variables as given, the household chooses $d \equiv\left(q^{b}, x^{b} ; q^{s}, x^{s} ; m_{+1} ; \sigma_{b}, \sigma_{s}\right)$ to solve the following dynamic programming problem:

$$
\begin{array}{r}
(P H) \quad v(m)=\max \left\{n \sigma_{b} A_{b}(T) u\left(q^{b}\right)-(1-n) \sigma_{s} A_{s}(T) c\left(q^{s}\right)\right. \\
\left.-n \phi\left(\sigma_{b}\right)-(1-n) \phi\left(\sigma_{s}\right)+\beta v\left(m_{+1}\right)\right\}
\end{array}
$$

subject to the constraints (14), (15), (17), (18) and the following:

$$
m_{+1}=m+(1-n) \sigma_{s} A_{s}(T) x^{s}-n \sigma_{b} A_{b}(T) x^{b}+L .
$$

The first term on the right-hand side of (20) is the utility of consumption, calculated as the total number of trades the household's buyers get, $\sigma_{b} A_{b}(T)$, times the utility of consumption in each trade. Similarly, the second term on the right-hand side of (20) is the household's disutility of production. The third and fourth terms are the search cost of sellers and buyers respectively. Eq (21) is the law of motion of the household's money balance. The household begins the period with a money balance $m$. In the period, the household's sellers acquire money through trade and the buyers spend money, the amounts of which are given by the second and third terms respectively. After trade, the household receives a lump-sum monetary transfer $L$.

\subsection{Optimal choices and surplus division}

Denote $\lambda$ as the Lagrangian multiplier associated with (14) and $\pi$ with (17). Because these constraints are applicable only when the household's members are in trade matches, we scale the multipliers by the number of the corresponding trade matches in order to incorporate them into the Lagrangian, i.e., multiplying $\lambda$ by $n \sigma_{b} A_{b}(T)$ and $\pi$ by $(1-n) \sigma_{s} A_{s}(T)$. Suppose that money is positively valued in the equilibrium, i.e., $\omega>0$ and $\Omega>0$. Then, the choices $\left(q^{b}, x^{b}\right)$ and $\left(q^{s}, x^{s}\right)$ satisfy the following first-order conditions:

$$
\begin{aligned}
& u^{\prime}=\frac{\omega+\lambda}{\Omega} c^{\prime}\left(q^{b}\right), \\
& c^{\prime}\left(q^{s}\right)=\frac{\omega-\pi}{\Omega} u^{\prime}, \\
& \lambda\left(\frac{m}{n}-x^{b}\right)=0, \\
& \pi\left(\frac{M}{N}-x^{s}\right)=0 .
\end{aligned}
$$

Eqs (24) and (25) are self-explanatory. To explain (22), note first that the constraint (15) must bind when $\omega>0$; otherwise, the household could increase utility by reducing the buyer's money offer. The equality of (15) implies that, for given $R^{s}$, a marginal unit of consumption good acquired by a proposing buyer $\operatorname{costs} c^{\prime}\left(q^{b}\right) / \Omega$ units of money. When proposing an additional unit of money, the buyer's household foregoes the future value of money, $\omega$, and faces a tighter trading 
restriction (14). Thus, $(\omega+\lambda)$ is the marginal cost of money to the proposing buyer's household, and the amount of money needed to acquire a marginal unit of consumption costs $(\omega+\lambda) c^{\prime}\left(q^{b}\right) / \Omega$. Eq. (22) requires this cost to be equal to the marginal utility of consumption acquired by such money.

Similarly, (18) must bind when $\omega>0$ and the condition implies that a proposing seller sells a marginal unit of good for $u^{\prime} / \Omega$ units of money. Eq. (23) requires that the marginal cost of production be equal to the value of the acquired money, given by the right-hand side which incorporates the cost of the constraint (17) to the proposing seller's household.

In symmetric equilibria, which we will focus on, $\omega=\Omega, x^{i}=X^{i}$ and $q^{i}=Q^{i}$, where $i \in\{b, s\}$. Then (22) and (23) imply that either $\lambda>0$ and $\pi>0$, or $\lambda=\pi=0$. In the first case, $q^{i}<q^{*}$, and in the second case, $q^{i}=q^{*}$, for $i=b, s$. Using these facts and (15), (16), (18) and (19), we can show that, when $\Delta \rightarrow 0, x^{b}=x^{s}=x$ and $q^{b}=q^{s}=q$. In addition, the following equation holds: ${ }^{13}$

$$
u(q)-\omega x=\frac{\theta u^{\prime}}{\theta u^{\prime}+(1-\theta) c^{\prime}(q)}[u(q)-c(q)],
$$

where $x=m / n$ if $\lambda>0$ and $q=q^{*}$ if $\lambda=0$.

An important property of the bargaining outcome is that the buyer's share of the match surplus is endogenous, as is evident in (26). To emphasize this endogenous share, denote it as

$$
\Theta(q) \equiv \frac{\theta u^{\prime}}{\theta u^{\prime}+(1-\theta) c^{\prime}(q)}
$$

Clearly, the buyer's share is bounded below by $\theta$ and is a decreasing function of $q$. Only when the trading constraint (14) does not bind is the buyer's share constant, in which case $\lambda=0, q=q^{*}$ and $\Theta=\theta$. When the trading constraint (14) binds, $q<q^{*}$ and so $\Theta(q)>\theta$. Moreover, since $q$ decreases with money growth, as shown later, the buyer's surplus share increases with money growth. Notice that the buyer's share is always equal to the constant $\theta$ if money is assumed to be indivisible, because then the constraint (14) is not meaningful.

The above features of the surplus share are established and explained in Shi (2001a). Let us repeat some of the explanations here, because the endogenous surplus share is critical to our analysis later. One explanation for why the money constraint affects $\Theta$ is that the constraint changes the buyer's threat point in bargaining. When the money constraint binds, the buyer can use the constraint to credibly limit his offer, so as to extract a larger share of the match surplus

\footnotetext{
${ }^{13}$ See Shi (2001a, Proposition 1) and Berentsen and Rocheteau (2001). The procedure is as follows. Imposing symmetry and eliminating $\left(R^{s}, R^{b}\right)$ from (15), (16), (18) and (19), we have two equations involving $\left(x^{b}, q^{b} ; x^{s}, q^{s}\right)$. If $\lambda>0$, then $x^{s}=x^{b}=m / n$ in a symmetric equlibrium, and so the two equations solve for $q^{b}$ and $q^{s}$ as functions of $m / n$ and $\Delta$. When $\Delta \rightarrow 0$, applying l'Hopital's rule to these solutions yields $q^{s} \rightarrow q^{b}$ and (26). If $\lambda=0$, then $\pi=0$ as well, and $q^{s}=q^{b}=q^{*}$ for all small $\Delta$. Substituting these for $\left(q^{s}, q^{b}\right)$ in the two equations involving $\left(x^{b}, q^{b} ; x^{s}, q^{s}\right)$, we can solve $\left(x^{b}, x^{s}\right)$ as functions of $\Delta$. When $\Delta \rightarrow 0$, applying l'Hopital's rule to these solutions yields $x^{s} \rightarrow x^{b}$ and (26) with $q=q^{*}$.
} 
than the unconstrained share $\theta .{ }^{14}$ Another explanation is that the seller, when it is his turn to propose, can ask for no more money than the buyer has, and so he must share a part of the cost associated with the money constraint. This reduces the seller's share below the unconstrained share $(1-\theta)$ and increases the buyer's share of surplus above the unconstrained share $(\theta)$. In fact, if we use (23) to substitute $c^{\prime}(q)$, then $\Theta=\theta /[1-(1-\theta) \pi / \omega]$, which shows that the buyer's surplus share increases with $(1-\theta) \pi / \omega$, the cost of the money constraint borne by the seller. With either explanation, higher money growth reduces the real money balance, makes the money constraint more binding, and hence increases buyers' surplus share.

To complete the characterization of the household's optimal choices, let us derive the envelope condition for $m$ as follows:

$$
\omega_{-1} / \beta=\omega+\sigma_{b} A_{b}(T) \lambda .
$$

This condition states simply that the marginal value of money in the current period is equal to the discounted future value of money plus the value that money has in alleviating the trading constraint (14) in the current period.

Finally, the household's search intensities satisfy the following conditions:

$$
\begin{aligned}
\phi^{\prime}\left(\sigma_{b}\right) & =A_{b}(T) \Theta(q)[u(q)-c(q)], \\
\phi^{\prime}\left(\sigma_{s}\right) & =A_{s}(T)[1-\Theta(q)][u(q)-c(q)] .
\end{aligned}
$$

These conditions equate the private, rather than the social, cost and benefit of search intensity. For example, the benefit to the household from increasing a buyer's search intensity is the number of trade matches such intensity generates, $A_{b}$, times the gain that the household gets from each of such trades, $\Theta[u(q)-c(q)]$. Thus, how the match surplus is divided between a buyer and a seller is important for the household's search decisions. In contrast, this division is irrelevant for the social optimum, as is clear from (12) and (13).

\subsection{Symmetric monetary equilibria}

Because all households are identical, it is natural to focus on symmetric equilibria.

Definition 1 A symmetric monetary equilibrium consists of an individual household's choices $\left\{d_{t}\right\}_{t=0}^{\infty}$, where $d=\left(q^{b}, x^{b} ; q^{s}, x^{s} ; m_{+1} ; \sigma_{b}, \sigma_{s}\right)$, other households' choices $\left\{D_{t}\right\}_{t=0}^{\infty}$, and the implied shadow prices $(\omega, \lambda, \pi ; \Omega, \Lambda, \Pi)$ such that the following requirements are met: (i) For every $t \geq 0$,

\footnotetext{
${ }^{14}$ To see how the trading constraint (14) changes the buyer's threat point, it is useful to consider the following Nash bargaining problem: $\max \left[u(q)-\omega x+\lambda\left(\frac{m}{n}-x\right)\right]^{\theta}[\omega x-c(q)]^{1-\theta}$. This cooperative problem yields the same solution as the sequential bargaining problem. Although $\lambda\left(\frac{m}{n}-x\right)=0$, the trading constraint affects how the buyer's threat point changes, at the margin, with the amount of money offered in the trade. Although other specifications of the threat points can also lead to endogenous shares, as Randall Wright suggested to us, our specification is simple and yet effective.
} 
$d_{t}$ solves the individual household's maximization problem $(P H)$, given $D$ and other capital-case variables; (ii) $d_{t}=D_{t}$ for all $t \geq 0$; and (iii) $0<\omega_{t-1} M_{t}<\infty$ for all $t$.

The requirement (i) is self-explanatory, while (ii) requires symmetry. To explain (iii), note that the real money balance in a household in period $t$ is $\omega_{t-1} m_{t} / \beta$. Thus, $\omega_{t-1} M_{t}>0$ requires that money be positively valued, and $\omega_{t-1} M_{t}<\infty$ requires that the real money balance be finite. The latter is necessary to ensure that the first-order conditions for the household's decisions indeed characterize the optimal decisions.

As in Shi (1999a) and Berentsen and Rocheteau (2001), a monetary equilibrium exists only for $\gamma \geq \beta$, and $\lambda>0$ if and only if $\gamma>\beta .^{15}$ If $\gamma=\beta$, there are a continuum of monetary equilibria with $\lambda=0$ that differ from each other in the initial value of money, $\omega_{-1}$, and the path of money spent in trade, $\left\{x_{t}\right\}_{t=0}^{\infty}$, but that have the same allocation $\left(q, \sigma_{b}, \sigma_{s}\right)$. Because this allocation can be approached from the equilibrium with $\lambda>0$ by reducing $\gamma$ to $\beta$, we will characterize only the equilibrium with $\lambda>0$.

Furthermore, we restrict our attention to the steady state. In the steady state, the real money balance, $\omega_{-1} M$, is constant. Using this fact and substituting $\lambda$ from (22), we can rewrite (28) as follows in the steady state:

$$
\frac{u^{\prime}}{c^{\prime}(q)}=1+\frac{1}{\sigma_{b} A_{b}(T)}\left(\frac{\gamma}{\beta}-1\right)
$$

The steady state equilibrium allocation, $\left(\omega x, \sigma_{b}, \sigma_{s}, q\right)$, is the solution to (26), (29), (30), and (31), with $T=(1-n) \sigma_{s} /\left(n \sigma_{b}\right)$. The following proposition, established in Appendix A, states the condition under which a monetary steady state exists.

Proposition 2 A monetary steady state exists if and only if $\beta \leq \gamma \leq \gamma_{\max }$, for some $\gamma_{\max }>\beta$ defined in Appendix A. The monetary steady state with the highest $q$ has the properties that $d T / d \gamma<0, d q / d \gamma<0, d\left(\frac{\sigma_{b}}{\sigma_{s}}\right) / d \gamma>0$, and $\lim _{\gamma \rightarrow \beta}(T, q)=\left(T^{*}, q^{*}\right)$, where

$$
T^{*} \equiv\left[\frac{1-\theta}{\theta}\left(\frac{1-n}{n}\right)^{\alpha-1}\right]^{1 / \alpha} .
$$

The existence region $\left[\beta, \gamma_{\max }\right] \ni \gamma$ can be very large and there can be multiple steady states. ${ }^{16}$ As in Shi (2001a), multiplicity arises from the dependence of the surplus shares on $\lambda$. If households believe that the money constraint will not bind severely, then sellers' surplus share will be high and households will choose to let sellers search intensively. This will increase aggregate supply of

\footnotetext{
${ }^{15}$ To see this, note that $\lambda \geq 0$ and so (28) implies $\omega_{t} \leq \beta^{-1} \omega_{t-1}$, where the equality holds only when $\lambda=0$. Interating on the inequality, we have $\omega_{t-1} M_{t} \leq(\gamma / \beta)^{t} \omega_{-1} M_{0}$. Given $0<\omega_{-1} M_{0}<\infty$, the equilibrium requirement $\omega_{t-1} M_{t}>0$ is satisfied for all $t$ only if $\gamma \geq \beta$. If $\lambda=0$, then $\omega_{t-1} M_{t}=(\gamma / \beta)^{t} \omega_{-1} M_{0}$, and so the equilibrium requirement $\omega_{t-1} M_{t}<\infty$ is satisfied for all $t$ only if $\gamma=\beta$.

${ }^{16}$ Consider an example where the matching function is Cobb-Douglas, $u(q)=u^{\prime} q$ and $c(q)=c_{0} q^{b}(b \geq 1)$. Then $\gamma_{\max }=\infty$ when $\alpha>\alpha_{0} \equiv 2-\eta+1 /(b-1)$ and $\gamma_{\max }<\infty$ when $\alpha \leq \alpha_{0}$. There are two steady states when $\alpha<\alpha_{0}$.
} 
goods and increase the purchasing power of money, which will indeed make the money constraint less binding. On the other hand, if households believe that the money constraint will bind severely, then sellers' surplus share will be low and households will choose low search intensity for sellers. This will reduce the purchasing power of money and hence indeed make the money constraint more binding.

In the following analysis, we will focus on the steady state with the highest $q$. There are two justifications. First, this steady state generates the least inefficiency among all possible steady states in the quantity of goods traded in each match. By focusing on such an equilibrium, we ensure that our welfare results are not caused by our selection of an inferior equilibrium. Second, the analytical properties of the steady state with the highest $q$ are invariant to whether there are multiple steady states.

Proposition 2 shows that, in the steady state we focus on, an increase in money growth makes the market thinner for buyers and reduces the quantity of goods traded in each trade match. These effects occur through two channels. One is the so-called hot-potato effect of inflation in Li (1997) or, similarly, the trading-opportunity effect in Shi (1997). That is, when money growth increases, the anticipated higher inflation induces households to trade away money more quickly than before, in an attempt to avoid the loss in the real value of money. To do so in a non-Walrasian economy, households increase buyers' search intensity relative to sellers', and this makes the market thinner for buyers. Similarly, a buyer in a trade match can demand fewer goods for the money. The second channel is the response of the surplus shares. When anticipated inflation rises with increased money growth, households anticipate that the money constraint will be more binding and hence will anticipate a lower surplus share for sellers. As a result, households will reduce the quantity of goods each seller produces in a trade and reduce sellers' search intensity relative to buyers', the latter of which makes the market thinner for buyers.

\section{Friedman Rule versus the Hosios Rule}

There are two sources of inefficiency in the monetary equilibrium, an inefficient quantity of goods in each trade $(q)$ and an inefficient number of trades resulting from inefficient search decisions $\left(\sigma_{b}, \sigma_{s}\right)$. In this section, we first examine separately the money growth rate that achieves efficiency in each of these two dimensions and then put the two together to find the optimal money growth rate.

\subsection{Friedman rule achieves the efficient quantity of trade}

Consider first the money growth rate that achieves the efficient quantity of goods in each trade. More precisely, we constrain the social planner to choose the same search intensities as those in the equilibrium and ask what money growth rate attains $q=q^{*}$ in the equilibrium. With this 
constraint on the social planner, the conditions for efficient search intensities, (12) and (13), no longer apply. Because the equilibrium quantity of trade is given by (31), it is evident that $q<q^{*}$ if and only if $\gamma>\beta$. We immediately have the following Lemma.

Lemma 1 When the social optimum is constrained to have the same search intensities as in the equilibrium, the Friedman rule attains efficiency. For all $\gamma>\beta$, the equilibrium quantity of goods exchanged in each trade match is inefficiently low. Social welfare decreases in the money growth rate.

The Friedman rule is efficient with constrained search intensities for precisely the same reason that it is efficient in a conventional (Walrasian) monetary model. That is, when the money growth rate obeys the Friedman rule, the real money balance $\left(\omega_{-1} M\right)$ is maximized, which makes the trading constraint (14) non-binding and so achieves the efficient quantity of trade. Note that the above lemma implies that the Friedman rule is efficient when search intensities are exogenous. Although this result has been established earlier by Shi (1997, p86), it has attracted only limited attention in the concurrent monetary search literature. Most search models still assume indivisible money, which forces the fraction of buyers in the economy to be equal to the quantity of money. This leads to a mis-interpretation of the optimum quantity of money, as we will show in section 5.4 .

\subsection{Hosios rule may require higher money growth than the Friedman rule}

Now suppose that the social planner is constrained to choose the same quantity of goods in each trade as in the equilibrium, but is able to choose search intensities. We ask what money growth rate can induce equilibrium search intensities to be the same as the planner's choices. Compare the equilibrium conditions for search intensities, (29) and (30), with the efficient counterparts, (12) and (13). It is evident that equilibrium search intensities are efficient if and only if $\Theta(q)=\eta(T)$, i.e., if and only if the Hosios rule is satisfied. Since both $q$ and $T$ are endogenous in the current case, there might be a money growth rate that generates such $q$ and $T$ that satisfy the Hosios rule. Denote this money growth rate as $\gamma^{h}$, if it exists.

The money growth rate $\gamma^{h}$ can be found as follows. Impose the Hosios rule $\Theta(q)=\eta(T)$ and use the formula of $\Theta(q)$ to solve for $q=q^{h}(T)$, where $q^{h}$ is defined by

$$
\frac{u^{\prime}}{c^{\prime}\left(q^{h}\right)}=\frac{(1-\theta) \eta(T)}{\theta[1-\eta(T)]}
$$

Substituting $q=q^{h}(T)$ into (29) and (30), and noting $\sigma_{s}=\sigma_{b} n T /(1-n)$, we can solve $\left(\sigma_{b}, \sigma_{s}, T\right)$. 
Denote these solutions as $\left(\sigma_{b}^{h}, \sigma_{s}^{h}, T^{h}\right) .{ }^{17}$ Then, (31) yields

$$
\gamma^{h}=\beta\left[1+\frac{\left[\eta\left(T^{h}\right)-\theta\right] \sigma_{b}^{h} A_{b}\left(T^{h}\right)}{\theta\left[1-\eta\left(T^{h}\right)\right]}\right] .
$$

Because money growth rates below $\beta$ are not feasible in equilibrium, we need $\gamma^{h} \geq \beta$. Clearly, $\gamma^{h} \geq \beta$ if and only if $\eta\left(T^{h}\right) \geq \theta$. Recall from Proposition 2 that equilibrium $T$ and $q$ are decreasing functions of $\gamma$. So, when $\eta\left(T^{h}\right) \geq \theta$, we have $\left(T^{h}, q^{h}\right) \leq\left(T^{*}, q^{*}\right)$, where $T^{*}$ is the equilibrium tightness at $\gamma=\beta$. If $\eta\left(T^{h}\right)<\theta$, even the lowest share for a buyer (achieved by the Friedman rule) is still greater than $\eta\left(T^{h}\right)$, and so the Hosios rule cannot be achieved by a feasible $\gamma$.

We summarize these results in the following lemma:

Lemma 2 When the social optimum is constrained to have the same quantity of goods in each trade as in the equilibrium, there exists a money growth rate that restores efficiency if and only if $\eta\left(T^{h}\right) \geq \theta$. This efficient money growth rate $\gamma^{h}$ exceeds the Friedman rule if $\eta\left(T^{h}\right)>\theta$ and is equal to the Friedman rule if $\eta\left(T^{h}\right)=\theta$. If $\eta\left(T^{h}\right)<\theta$, there is no feasible money growth rate that achieves efficiency and, among all feasible rates, the Friedman rule brings the equilibrium closest to the efficient allocation, with an efficient $q^{*}$ and an inefficiently low $T^{*}$.

The condition $\eta\left(T^{h}\right) \geq \theta$ imposes restrictions on parameters. If the matching technology has a constant elasticity $\eta$, as in the Cobb-Douglas matching function, then $\eta\left(T^{h}\right) \geq \theta$ if and only if $\eta \geq \theta$. To illustrate this condition when $\eta(T)$ is endogenous, consider the example where the matching function has additive matching rates. Then, $T^{h}=\left(\frac{1-n}{n}\right)^{(\alpha-1) /(\alpha+1)}$, and so $\eta\left(T^{h}\right) \geq \theta$ if and only if

$$
n \leq\left[1+\left(\frac{\theta}{1-\theta}\right)^{(\alpha+1) /(\alpha-1)}\right]^{-1} .
$$

It is important to understand why, in some cases, money growth must be higher than the Friedman rule in order to induce efficient search decisions. Consider the example of a constant elasticity $\eta>\theta$. If money growth obeys the Friedman rule, buyers are compensated by a surplus share $\Theta\left(q^{*}\right)=\theta$, which is lower than their share of contribution to the trade matches, $\eta$. So, buyers' search intensity is inefficiently low. If, instead, money supply grows at a slightly higher rate than the Friedman rule, the real money balance is lower, and so the trading constraints on money, (14) and (17), will be more binding. Because sellers share a part of the cost of those money constraints, as explained before, sellers' share of the surplus falls and buyers' share rises. (The function $\Theta(q)$ is a decreasing function of $q$ and hence an increasing function of $\gamma$.) This brings the surplus division closer to the Hosios rule, and hence the search intensities closer to the

\footnotetext{
${ }^{17}$ These solutions exist and are unique. To see this, divide (29) by (30) and substitute $q=q^{h}(T)$. We have $T^{\alpha-1}=\left(\frac{1-n}{n}\right)^{\alpha-1} f(T)$, where $f($.$) is defined in (8). With the assumptions on f$, it is evident that this equation has a unique solution $T^{h} \in(0, \infty)$. Then (29) and (30) give the unique solutions $\left(\sigma_{b}^{h}, \sigma_{s}^{h}\right)$. We assume that $\gamma^{h} \leq \gamma_{\max }$
} 
efficient ones. Note that, to increase buyers' share of surplus, inflation must be increased rather than decreased. However, since inflation also reduces the total surplus in the match, the size of a buyer's surplus may either increase or decrease with inflation.

\subsection{First-best and second-best policies}

Let us now put the two dimensions of efficiency together and examine optimal monetary policy. We start with the following proposition:

Proposition 3 The monetary equilibrium can attain the social optimum if and only if $\gamma=\beta$ and $\eta\left(T^{*}\right)=\theta$, where $T^{*}$ is the equilibrium tightness at $\gamma=\beta$, defined in (32).

This proposition comes from combining Lemmas 1 and 2, and hence the proof is omitted. Those lemmas imply that the equilibrium attains the social optimum if and only if $\gamma=\gamma^{h}=\beta$. For $\gamma^{h}=\beta$, it is necessary and sufficient that $\eta\left(T^{h}\right)=\theta$ when $q=q^{*}$. By definition, $T^{h}=T^{*}$ if $q=q^{*}$. Thus, the equilibrium attains the first best if and only if it satisfies both the Friedman rule $(\gamma=\beta)$ and the Hosios rule (i.e., $\eta\left(T^{*}\right)=\theta$ ).

When $\eta\left(T^{*}\right) \neq \theta$, the monetary equilibrium cannot achieve the first best, and so a money growth rate is optimal only in the second-best sense. To examine the second-best policy, let $\mathcal{W}(\gamma)$ be the social welfare level generated by an equilibrium with a money growth rate $\gamma \geq \beta$. Using (29) and (30), we can calculate:

$$
\mathcal{W}^{\prime}(\gamma)=\mathcal{M}\left(u^{\prime}-c^{\prime}\right) \frac{d q}{d \gamma}+[\eta(T)-\Theta(q)](u-c) \mathcal{M} \frac{\sigma_{s}}{\sigma_{b}} \frac{d\left(\sigma_{b} / \sigma_{s}\right)}{d \gamma}
$$

The first term on the right-hand side captures the welfare effect of money growth through the quantity of goods in each trade. This welfare effect is strictly negative for all $\gamma>\beta$ and zero at $\gamma=\beta$, because $d q / d \gamma<0$ and $u^{\prime}>c^{\prime}$ for all $\gamma>\beta$ while $u^{\prime}=c^{\prime}$ at $\gamma=\beta$. The second term on the right-hand side of (35) captures the welfare effect of money growth through search decisions. This welfare effect is ambiguous, depending on whether $\eta(T)>\Theta(q)$. Although money growth increases buyers' search intensity relative to sellers', as stated in Proposition 2, such an increase in $\sigma_{b} / \sigma_{s}$ increases welfare if and only if $\eta(T)>\Theta(q)$. The second-best policies can be summarized in the following proposition (see Appendix A for a proof):

Proposition 4 If $\eta\left(T^{*}\right)>\theta$, the optimal (second-best) money growth rate exceeds the Friedman rule and is strictly lower than $\gamma^{h}$ defined in (34). If $\eta\left(T^{*}\right)<\theta$, the optimal (second-best) money growth rate obeys the Friedman rule. Moreover, $\eta\left(T^{*}\right)>\theta$ if and only if $\eta\left(T^{h}\right)>\theta$.

The difference between the two cases $\eta\left(T^{*}\right)<\theta$ and $\eta\left(T^{*}\right)>\theta$ is subtle, although the violation of the Hosios rule is the common cause of inefficiency in both cases. When $\eta\left(T^{*}\right)<\theta$, the money growth rate that achieves the Hosios rule is not feasible - it would destroy the monetary 
equilibrium. The Friedman rule is optimal in this case, because it achieves the efficient quantity of goods in each trade and, at the same time, brings the equilibrium closer to the Hosios rule than does any other feasible money growth rate. When $\eta\left(T^{*}\right)>\theta$, in contrast, it is feasible to choose the money growth rate $\gamma^{h}$ that achieves the Hosios rule, but it is not optimal to do so. At the rate $\gamma^{h}$, the quantity of goods in each trade is too inefficiently low to be justified by the improved efficiency in the number of trades. Neither is it optimal to choose the Friedman rule, because the number of trades under the Friedman rule is too inefficient to be justified by the efficient quantity of goods in each trade. The second-best money growth rate makes the optimal compromise between these two dimensions of efficiency, and so it lies between $\beta$ and $\gamma^{h}$.

Proposition 4 also states that $\eta\left(T^{*}\right)>\theta$ if and only if $\eta\left(T^{h}\right)>\theta$. This is an alternative statement of the fact that the inefficiency in search decisions is the only possible cause for optimal money growth to exceed the Friedman rule. If the search inefficiency induces the constrained optimum in Lemma 2 to call for $\gamma^{h}>\beta$, then the unconstrained optimum must also require $\gamma>\beta$ as long as it values the search efficiency. That is, $\eta\left(T^{h}\right)>\theta$ implies $\eta\left(T^{*}\right)>\theta$. On the other hand, if $\eta\left(T^{h}\right)<\theta$, the constrained optimum calls for $\gamma^{h}=\beta$ to minimize the search inefficiency. To value this search efficiency, the unconstrained optimum must not require $\gamma>\beta$ in this case, and so $\eta\left(T^{*}\right)<\theta$.

\subsection{The misinterpretation of the optimum quantity of money in indivisible- money models}

The optimum quantity of money described in previous sections is very different from that in search models with indivisible money, such as Kiyotaki and Wright (1993), Shi (1995) and Trejos and Wright (1995). By forcing the fraction of buyers to be the same as the stock of money, the assumption of indivisible money made those models mistake the optimal fraction of buyers for the optimum quantity of money. To illustrate this mistake, we model the search decision in this subsection as the choice of the fraction of buyers, $n$, rather than the search intensity. ${ }^{18}$ This exercise also shows that our main results are robust to whether the search decision is modelled as a choice of the search intensity or of the composition of agents. To simplify the analysis, we assume in this subsection that search intensities are exogenously fixed at $\sigma_{b}=\sigma_{s}=\Sigma_{b}=\Sigma_{s}=1$. In this case, the tightness of the market is $T=(1-N) / N$. Also, note that $\phi(1)=0$.

The efficient $N$ equates the marginal social surplus generated by a buyer to that by a seller, because an increase in the number of buyers reduces the number of sellers one for one. An additional buyer contributes to the number of trades by $K_{b}$ and hence to social welfare by $K_{b}[u(Q)-c(Q)]$. Similarly, an additional seller contributes to social welfare by $K_{s}[u(Q)-c(Q)]$. Equating these

\footnotetext{
${ }^{18}$ Shi (1997) analyzes this choice $n$ in a divisible-money search model. Although one can deduce the fallacy of indivisible-money models by comparing their results with those in Shi (1997), it is useful to document the fallacy here explicitly.
} 
two surpluses and expressing the result in terms of $\eta$, we have the following condition for the efficient $N$ :

$$
N=\eta(T)
$$

In contrast, an individual household equates the private gain and loss associated with a higher $n$. The private gain is $A_{b}[u(q)-(\omega+\lambda) x]$. The term $\lambda x$ is present because an increase in $n$ reduces the money balance that each individual buyer of the household carries into the trade match and hence makes the trading constraint (14) more binding. The private loss from a higher $n$ is the surplus generated by an additional producer, which is $A_{s}[\omega x-c(q)]$. Equating such private gain and loss, and substituting $\lambda$ and $\omega x$ from (22) and (26), we have the following condition for $n$ (or $N)$ in the symmetric equilibrium:

$$
\frac{N}{1-N}=\frac{\Theta(q)}{1-\Theta(q)}\left\{1-\left(\frac{u^{\prime}}{c^{\prime}(q)}-1\right)\left[\frac{u(q)}{(u(q)-c(q)) \Theta(q)}-1\right]\right\} .
$$

Proposition 3 continues to hold. That is, the first-best allocation requires the Friedman rule and the Hosios rule to both hold. First, money growth must be $\gamma=\beta$ in order for the quantity of goods in each trade to be efficient, i.e., for $q=q^{*}$. Second, when $\gamma=\beta$, we have $\Theta=\theta$, and so (37) becomes $N^{*}=\theta$, where $N^{*}$ is the fraction of buyers at $\gamma=\beta$. Comparing this with the efficient counterpart (36), it is evident that the equilibrium $N$ is efficient if and only if $\eta\left(T^{*}\right)=\theta$, i.e., if and only if the Hosios condition is satisfied.

Let us now tailor the above efficiency result to the case often examined in indivisible-money search models, i.e., the case where $\theta=1 / 2$ and the matching function has additive matching rates. In this case, $\eta(T)=T /(1+T)$, and so the efficient fraction of buyers is $N^{*}=1 / 2$. This number, $1 / 2$, is exactly what indivisible-money models described as the optimum quantity of money in the absence of barter (see Kiyotaki and Wright 1993). Our model shows that the optimum quantity of money obeys the Friedman rule, instead. Clearly, this fallacy of indivisible-money models arises from their inability to distinguish the fraction of buyers from the stock of money. ${ }^{19}$

Finally, when $\eta\left(T^{*}\right) \neq \theta$, the monetary equilibrium can only attain the second best. As before, the second-best policy makes the optimal trade-off between the efficiency in $q$ and the efficiency in $N$, and the second-best money growth rate rate can exceed the Friedman rule when $\theta$ is sufficiently low. However, the general characterization of the second-best policy is not very revealing, because an increase in the money growth rate can either increase or decrease $N$. We omit such an analysis and refer to Shi (1997) for a similar analysis.

\footnotetext{
${ }^{19}$ If a double coincidence of wants occurs with probability $r^{2}$, a monetary equilibrium in this special economy is efficient if and only if $\gamma=\beta$ and $N^{*}=\left(\frac{1}{2}-r\right) /(1-r)$ (see Shi 1997, p92). Again, the indivisible-money models mistake such an efficient fraction of buyers for the optimum quantity of money (see Kiyotaki and Wright 1993).
} 


\section{Introducing Double Coincidence of Wants}

When all trade matches involve only single coincidence of wants, producers and money holders are symmetric in trade in the sense that every trade involves a buyer and a seller. When barter can be successful, however, every trade has at least one producer but not necessarily a money holder. The Hosios rule must be modified to accommodate this asymmetry. We show how this can be done in this section. Let us return to the setup where the fraction of buyers is fixed and search intensities are endogenous. To avoid confusion, we now refer to an agent who is able to produce as a producer (instead of a seller) and an agent who holds money as a money holder (instead of a buyer). However, we still use the symbols $S$ and $B$ to denote the number of agents in these two groups, respectively.

\subsection{Matching technology}

Assume that tastes and production technologies are such that barter is possible between some producers. In particular, when a producer A randomly meets another producer B and happens to be able to produce B's consumption good, B can also produce A's consumption good with a conditional probability $r \in(0,1)$ (conditional on that A can produce B's consumption good). ${ }^{20}$ Since barter is possible, we extend the notion of trade matches to include both monetary and barter trade matches.

To specify the matching function, note that social welfare depends on the output level, rather than on the number of matches per se. For the analysis on efficiency, it is useful to count the number of times at which production takes place, rather than the number of trade matches. This requires us to count each barter trade twice. For this reason, we call the number of times of production the effective number of trade matches and assume that it is given by the following matching function:

$$
\mathcal{M}\left(B \Sigma_{b}+r S \Sigma_{s}, S \Sigma_{s}\right) .
$$

We assume that $\mathcal{M}(.,$.$) has all the properties assumed before. Clearly, the matching function in$ previous sections corresponds to the special case $r=0$.

To understand the matching function, note first that every production involves at least a producer, which is why producers' search units appear as the second input of the function. Pick an arbitrary producer, say $A$, and consider a match in which the partner wishes to consume $A$ 's goods. Producer $A$ produces, i.e., the match is a trade match, if the partner is one of the

\footnotetext{
${ }^{20}$ For example, consider the following environment. Each type $h$ household produces only type $h$ good, as before, but its consumption good is randomly drawn at the beginning of each period from the $(H-1)$ types other than $h$. All type $h$ households have the same taste realization and so, as before, there is no gain for two households of the same type to trade with each other. With this modification, the conditional probability $r$ is equal to $1 /(H-1)$. The (unconditional) probability of a successful barter trade between two randomly matched producers is $r / H$.
} 
following two types. The first is a money holder. The total number of such potential partners is $B \Sigma_{b}$. The second type is a producer who can produce the good that $A$ wishes to consume. Since each producer can produce the good that $A$ wants with probability $r$ (conditional on that $A$ can produce the good the partner wants), the total number of such potential partners is $r S \Sigma_{s}$. Thus, the first input of the matching function is the total search units of the partners with whom an arbitrary producer can have a trade match. ${ }^{21}$

The function (38) also generalizes the matching technology commonly used in search money models, such as Kiyotaki and Wright (1993). To see this, it is useful to decompose $\mathcal{M}=\mathcal{M}_{d}+\mathcal{M}_{m}$, where $\mathcal{M}_{d}$ is the number of producers involved in barter trades $\mathcal{M}_{m}$ the number of producers in monetary trades. From the above explanation, it is clear that an arbitrary producer $A$ has a barter trade with probability $r S \Sigma_{s} /\left(B \Sigma_{b}+r S \Sigma_{s}\right)=r T /(1+r T)$, and a monetary trade with probability $1 /(1+r T)$, both being conditional on that producer $A$ can produce the good that the partner wants to consume. Thus,

$$
\begin{aligned}
\mathcal{M}_{d} & =\frac{r T}{1+r T} \mathcal{M}\left(B \Sigma_{b}+r S \Sigma_{s}, S \Sigma_{s}\right)=r S \Sigma_{s} \mathcal{M}\left(1, \frac{T}{1+r T}\right) \\
\mathcal{M}_{m} & =\frac{1}{1+r T} \mathcal{M}\left(B \Sigma_{b}+r S \Sigma_{s}, S \Sigma_{s}\right)=B \Sigma_{b} \mathcal{M}\left(1, \frac{T}{1+r T}\right) .
\end{aligned}
$$

The matching technology in Kiyotaki and Wright (1993) corresponds to the special case where $\mathcal{M}(x, y)=z x y /[x+(1-r) y]$ and $\Sigma_{b}=\Sigma_{s}=1$. In this case, $\mathcal{M}_{d}=r z(1-N)^{2} H$ is the number of producers involved in barter trades and $\mathcal{M}_{m}=z N(1-N) H$ is the number of producers in monetary trades. ${ }^{22}$

Now we can define the average matching rates per search intensity as before. Let $A_{i j}$ denote the average rate at which a unit of search intensity of type $i$ agents receives a type $j$ trade match, where $i \in\{b, s\}$ refers to money holders or producers and $j \in\{d, m\}$ refers to barter trades or monetary trades. Then,

$$
\begin{aligned}
A_{s d} & =\frac{\mathcal{M}_{d}}{S \Sigma_{s}}=r \mathcal{M}\left(1, \frac{T}{1+r T}\right) \\
A_{s m} & =\frac{\mathcal{M}_{m}}{S \Sigma_{s}}=\frac{1}{T} \mathcal{M}\left(1, \frac{T}{1+r T}\right) \\
A_{b m} & =\frac{\mathcal{M}_{m}}{B \Sigma_{b}}=\mathcal{M}\left(1, \frac{T}{1+r T}\right) .
\end{aligned}
$$

\footnotetext{
${ }^{21}$ An implicit assumption here is that every search unit, regardless of whether it is a producer's or a money holder's, has the same matching probability with a producer. If, instead, every producer's search unit receives the match at rate $R$ relative to a money holder's search unit, then the matching function should be modified as $M\left(B \Sigma_{b}+\operatorname{Rr} S \Sigma_{s}, S \Sigma_{s}\right)$. This modification does not change our analytical results.

${ }^{22}$ Many search money models impose a further restriction $r=z$, where $z$ is the probability with which an agent wants to consume the good produced by a randomly selected partner. However, another variation, with $z=1 / H$ and $r=1 /(H-1)$, is also possible (see footnote 20 ).
} 
Note that $A_{b d}$ is not defined, because a money holder is never involved in a barter trade. Also, $A_{s d}=r T A_{s m}$. Finally, for a money holder who searches with intensity $\sigma_{b}$, his probability to trade is $\sigma_{b} A_{b m}$. For a producer who searches with intensity $\sigma_{s}$, his probability of having a monetary trade is $\sigma_{s} A_{s m}$ and a barter trade $\sigma_{s} A_{s d}$.

\subsection{Search externalities and the social optimum}

Adding a money holder in the economy generates a crowding-out between the two types of trade matches, as well as within monetary trade matches. To see this, denote $K_{i j}$ as money holders' $(i=b)$ or producers' $(i=s)$ marginal contribution to the number of type- $j$ trade matches, where $j \in\{m, d\}$. Then,

$$
K_{b j}(T)=\partial \mathcal{M}_{j} / \partial\left(B \Sigma_{b}\right), \quad K_{s j}(T)=\partial \mathcal{M}_{j} / \partial\left(S \Sigma_{s}\right) .
$$

$>$ From (39) and (44), it can be checked that $K_{b d}<0$, and so money holders crowd out barter trades. For every money holder who finds a monetary trade match, a producer is taken away from possible barter trades with probability $r T$. This negative externality between the two trade types is in addition to the negative externality that the particular monetary trade generates on other monetary trades.

Another way to see the crowding-out is to compute money holders' and producers' shares of contribution to each type of trade matches. These shares are as follows, for $j \in\{m, d\}$ :

$$
\eta_{b j}(T)=\frac{K_{b j}(T) B \Sigma_{b}}{\mathcal{M}_{j}}, \quad \eta_{s j}(T)=\frac{K_{s j}(T) S \Sigma_{s}}{\mathcal{M}_{j}}=1-\eta_{b j}(T) .
$$

The fact $\eta_{b d}<0$ captures money holders' crowding-out on barter trades. For the same reason, producers' share in barter matches is greater than 1 and, in fact, one can verify that $\eta_{s d}=1+\eta_{s m}$. In contrast, the shares in monetary trade matches satisfy $\eta_{b m}, \eta_{s m} \in[0,1]$, as before. The marginal contributions, the $K$ 'es, and the average matching rates, the $A$ 'es, are related to each other through the following relationships:

$$
K_{b m}=\eta_{b m} A_{b m}, \quad K_{s m}=\eta_{s m} A_{s m}, \quad K_{s d}=\eta_{s d} A_{s d} .
$$

We can adapt the analysis in section 3 to analyze the social optimum. Social welfare is measured by the following steady state utility per period per household:

$$
\mathcal{W}=\frac{1}{H}\left\{\mathcal{M}_{m}[u(Q)-c(Q)]+\mathcal{M}_{d}\left[u\left(Q_{d}\right)-c\left(Q_{d}\right)\right]\right\}-N \phi\left(\Sigma_{b}\right)-(1-N) \phi\left(\Sigma_{s}\right),
$$

where $\left(\mathcal{M}_{d}, \mathcal{M}_{m}\right)$ are given by (39) and (40), and $Q_{d}$ denotes the quantity of goods produced by each of the producers in a barter trade. Clearly, the social optimum requires $Q_{d}=Q=q^{*}$. To facilitate discussion, we will set only $Q_{d}$ to $q^{*}$ and, for the moment, keep the notation $Q$. The efficient search intensities satisfy the following equations:

$$
\begin{aligned}
& \phi^{\prime}\left(\Sigma_{b}\right)=K_{b m}(T)[Q-c(Q)]+K_{b d}(T)\left[q^{*}-c\left(q^{*}\right)\right], \\
& \phi^{\prime}\left(\Sigma_{s}\right)=K_{s m}(T)[Q-c(Q)]+K_{s d}(T)\left[q^{*}-c\left(q^{*}\right)\right] .
\end{aligned}
$$




\subsection{Modified Hosios rule and optimal money growth}

We re-examine the monetary equilibrium. A typical household's maximization problem is similar to $(P H)$, with $A_{b m}$ replacing $A_{b}$ and $A_{s m}$ replacing $A_{s}$. The objective function contains an additional term, $(1-n) \sigma_{s} A_{s d}\left[u\left(q_{d}\right)-c\left(q_{d}\right)\right]$, which is the total surplus that the household obtains through barter. The barter quantity $q_{d}$ is determined through sequential bargaining similar to that for a monetary trade, where the proposing agent proposes two quantities, one for himself to produce and the other for the partner to produce. Given the symmetry between two producers, it is natural to assume that each faces the same breakdown probability after he rejects the partner's offer. In this case, the two quantities are both equal to $q_{d}=q^{*}$ (e.g., Shi 1995 and Trejos and Wright 1995).

The quantity of goods exchanged in a monetary trade still satisfies (31) in the steady state, with $A_{b m}$ replacing $A_{b}$. So, for this quantity to be efficient, the money growth rate must obey the Friedman rule. The household's search intensities satisfy:

$$
\begin{aligned}
\phi^{\prime}\left(\sigma_{b}\right) & =A_{b m}(T) \Theta(q)[u(q)-c(q)], \\
\phi^{\prime}\left(\sigma_{s}\right) & =A_{s m}(T)[1-\Theta(q)][u(q)-c(q)]+A_{s d}(T)\left[u\left(q^{*}\right)-c\left(q^{*}\right)\right] .
\end{aligned}
$$

Compare the above equilibrium conditions with the corresponding efficient conditions (45) and (46). A stark contrast is that the barter surplus appears in the social planner's choice of money holders' search intensity but not in the corresponding choice of the household. The social planner takes into account money holders' crowding-out on barter trades, as captured by $K_{b d}<0$. Individual households, however, ignore this externality. If money holders are compensated with their contributions to monetary trades alone, i.e., if $\Theta=\eta_{b m}$, then their search intensity is inefficiently high. Similarly, the crowding-out implies $\eta_{s d}>1$, and so producers' search intensity is inefficiently low under $1-\Theta=\eta_{s m}$. Therefore, the Hosios rule in the usual form, $\Theta=\eta_{b m}$, no longer internalizes all search externalities.

To implement efficient search intensities, equate the right-hand side of the equilibrium condition (47) to that of (45), and (48) to (46). Doing so yields a single requirement, as follows: ${ }^{23}$

$$
\Theta(q)=\eta_{b m}(T)+r T \eta_{b d}(T) \frac{u\left(q^{*}\right)-c\left(q^{*}\right)}{u(q)-c(q)} .
$$

This is the modified Hosios rule, under which equilibrium search intensities are efficient. Because $\eta_{b d}<0$, the last term in (49) is negative, and so the modified Hosios rule requires $\Theta<\eta_{b m}$. The difference between the efficient $\eta_{b m}$ and $\Theta$ is the fraction of output which a monetary trade crowds out on barter.

The modified Hosios rule illustrates two potential reasons why the original form of the Hosios rule can generate inefficiency in search decisions when there are heterogeneous trades. One is that

\footnotetext{
${ }^{23}$ To get the requirement, we use the facts that $K_{b m} / A_{b m}=\eta_{b m}$ and $K_{b d} / A_{b m}=r T \eta_{b d}$.
} 
it fails to take into account the potential difference in the quantity of goods between heterogeneous trades. Since it is the social surpluses from various trades, not the number of trades per se, that are important for social welfare, the search externalities must be weighted by the social surpluses of the corresponding trades in order to determine the efficient compensation. If different types of trades involve different quantities of goods, then the search externalities involving these trades must be weighted differently in the efficient compensation scheme, as is evident in (49). Although such heterogeneous weighting scheme drops out in the first-best allocation in our model, as $q=q^{*}$ in this case, it is not a robust result. In an extension where tastes are asymmetric (e.g., Berentsen and Rocheteau 2001a), almost all trades involve different quantities of goods and so they must be weighted differently for efficiency considerations. Even in our model, the heterogeneous weighting scheme is important in the second-best allocation, where $q \neq q^{*}$.

The second reason why the original form of the Hosios rule is not reliable is that it equates the surplus share to the share or elasticity of a matching function. When there are heterogeneous trades and not all agents are involved in all trades, it is not clear how to calculate a share or an elasticity of a matching function that is comparable to the surplus share. To illustrate this point, consider the case where $q=q^{*}$, which occurs under the Friedman rule. Then, the modified Hosios rule (49) can be written as:

$$
\Theta\left(q^{*}\right)=\left(K_{b m}+K_{b d}\right) / A_{b m}
$$

This expression for the efficient compensation is more reliable than the original form of the Hosios rule. Intuitively, it requires that each money holder's surplus in a period, $\Theta\left(q^{*}\right) A_{b m}\left[u\left(q^{*}\right)-c\left(q^{*}\right)\right]$, be equal to the corresponding contribution to social surplus, $\left(K_{b m}+K_{b d}\right)\left[u\left(q^{*}\right)-c\left(q^{*}\right)\right]$. Note that only monetary trades are counted in the calculation of a money holder's average matching rate, because a money holder gets the share $\Theta$ of surplus only in monetary trades. In contrast, both types of trades are counted in the calculation of a money holder's marginal contribution, in order to incorporate all externalities that a money holder's search decision creates on trades.

Nevertheless, if one wants to express (50) in terms of $\eta$, it is as follows:

$$
\Theta\left(q^{*}\right) /(1+r T)=\eta_{b}(T)
$$

where $\eta_{b} \equiv \frac{\partial \mathcal{M} / \partial\left(B \Sigma_{b}\right)}{\mathcal{M} /\left(B \Sigma_{b}\right)}$ is the share of money holders' search intensities to the effective number of all trade matches. Note that a money holder's surplus share is re-scaled by a factor $1 /(1+r T)$, the fraction of trades that are monetary trades, in order to convert the share into an average surplus share over all trades.

With the above modification of the Hosios rule, we can easily adapt the results in section 5 into the current environment. First, the monetary equilibrium achieves the first-best allocation if and only if $\gamma=\beta$ and $\eta_{b}\left(T^{*}\right)\left(1+r T^{*}\right)=\theta\left(=\Theta\left(q^{*}\right)\right)$, where $T^{*}$ is the equilibrium market tightness at $\gamma=\beta$. Second, if $\eta_{b}\left(T^{*}\right)\left(1+r T^{*}\right)<\theta$, the Friedman rule is optimal, achieving the 
second best. Third, if $\eta_{b}\left(T^{*}\right)\left(1+r T^{*}\right)>\theta$, the optimal (second-best) money growth rate lies in $\left(\beta, \gamma^{h}\right)$. The rate $\gamma^{h}$ is calculated similarly to (34), using instead the modified Hosios rule (49) and the conditions (47)-(48) to solve for $\left(T^{h}, \sigma_{b}^{h}, \sigma_{s}^{h}, q^{h}\left(T^{h}\right)\right)$.

\section{Discussion}

In this section we discuss a different trading mechanism and its implication for the results in our paper. Our model underlies the following decision structure. All households determine simultaneously their money holdings and the bargaining strategies for their members. After this the members of the household carry out the strategies given to them by their households. Our formulation involves some commitment because we assume that the households cannot condition their bargaining strategies on the specific characteristics of their members future bargaining partners. This commitment enable buyers to obtain the full return that an additional unit of money provides to a match.

An alternative decision structure suggested by Rauch (2000) is to assume that the bargaining strategies are determined ex post (after the matches have been formed). This decision structure creates a so called hold-up problem because when a buyer, in an out-of-equilibrium match, ${ }^{24}$ brings an additional unit of money into a match, he does not receive the entire surplus that this additional unit creates for the match, unless he has all the bargaining power. If buyers cannot obtain the full return that an additional unit of money provides to the match, the purchasing power of money will be inefficiently low in equilibrium, and the Friedman rule will fail to generate the first-best allocation of resources. ${ }^{25}$

To derive the envelope condition for the decision structure suggested by Rauch (2000), we have to derive the derivatives $\frac{d q^{b}}{d m}$ and $\frac{d q^{s}}{d m}$, respectively. To derive $\frac{d q^{b}}{d m}$ we consider a match between a buyer of the representative household and a seller from some other household. Furthermore, we set $x^{b}=m / n$ because in the monetary equilibrium the constraint $x^{b} \leq m / n$ is binding. The terms of trade in such a match satisfy

$$
\theta u^{\prime}\left[-c\left(q^{b}\right)+\Omega \frac{m}{n}\right]=(1-\theta) c^{\prime}\left(q^{b}\right)\left[u\left(q^{b}\right)-\omega \frac{m}{n}\right] .
$$

Totally differentiate (52), and note that in a symmetric equilibrium $M=m, \Omega=\omega, N=n$, $q^{b}=q$, to get

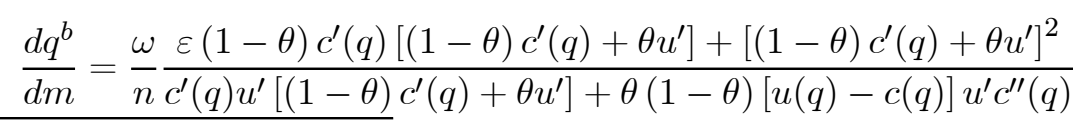

\footnotetext{
${ }^{24}$ In equilibrium all buyers hold the same amount of money. Nevertheless, to determine the value of money one has to consider matches where the buyers of the representative household hold different amounts of money that what is expected in equilibrium.

${ }^{25}$ For a detailed discussion of how the hold-up problem affects the validity of the Friedman rule see Berentsen and Rocheteau (2001).
} 
where $\varepsilon=\frac{d \omega}{d m} \frac{m}{\omega}$ is the elasticity of the marginal value of money with respect to $m$. We can distinguish between a hold-up effect and a strategic effect. The second term in the numerator represents the hold-up effect. It measure how the buyers consumption changes when $m$ changes holding $\omega$ constant. The strategic effect is represented by the first term in the numerator and measure how the terms-of-trade are affected when the marginal value of money changes in an out-of-equilibrium match. ${ }^{26}$

The tricky part is to derive $\varepsilon$ and we are not able to do so. Note, however, that the strategic effect reduces the additional consumption that a buyer receives in a out-of-equilibrium match, and consequently will depress the equilibrium value of money if the marginal value of money is decreasing $(\varepsilon<0) .{ }^{27}$

To derive $\frac{d q^{s}}{d m}$ we consider a match between a seller of the representative household and a buyer from some other household. The terms of trade in such a match satisfy

$$
\theta u^{\prime}\left[-c\left(q^{s}\right)+\omega \frac{M}{N}\right]=(1-\theta) c^{\prime}\left(q^{s}\right)\left[u\left(q^{s}\right)-\Omega \frac{M}{N}\right] .
$$

Totally differentiate (54) and then impose $M=m, \Omega=\omega, N=n, q^{s}=q$ to get

$$
\frac{d q^{s}}{d m}=\frac{\omega}{n} \frac{\theta \varepsilon\left[(1-\theta) c^{\prime}(q)+\theta u^{\prime}\right]}{c^{\prime}(q)\left[(1-\theta) c^{\prime}(q)+\theta u^{\prime}\right]+\theta(1-\theta)[u(q)-c(q)] c^{\prime \prime}(q)}
$$

Note that if the marginal value of money is decreasing $(\varepsilon<0)$, then $\frac{d q^{s}}{d m}<0$. Thus, if $\varepsilon<0$, the strategic effect reduces the quantity that a seller has to produce in a out-of-equilibrium match, and consequently will increase the equilibrium value of money.

At the symmetric equilibrium the envelope condition satisfies:

$$
\frac{\omega_{-1}}{\beta}=\omega+\sigma_{b} A_{b}(T) \lambda-n \sigma_{b} A_{b}(T) \frac{\omega+\lambda}{\Omega} R_{m}^{s}-(1-n) \sigma_{s} A_{s}(T) \frac{\omega-\pi}{\Omega} R_{m}^{b}
$$

where $R_{m}^{s}=\frac{\omega}{n}-c^{\prime}(q) \frac{d q^{b}}{d m}$ and $R_{m}^{b}=u^{\prime} \frac{d q^{s}}{d m} \cdot{ }^{28} \quad$ Replace $R_{m}^{s}$ and $R_{m}^{b}$ and use the first-order conditions from the household problem to replace $\lambda, \frac{\omega+\lambda}{\Omega}$, and $\frac{\omega-\pi}{\Omega}$ respectively, to get

$$
\frac{\omega_{-1}}{\beta}=\omega-\sigma_{b} A_{b}(T) \omega+n \sigma_{b} A_{b}(T) u^{\prime} \frac{d q^{b}}{d m}-(1-n) \sigma_{s} A_{s}(T) c^{\prime}(q) \frac{d q^{s}}{d m}
$$

In the steady-state the real value of money $\omega_{-1} m$ is constant and we can express the envelope condition as follows

$$
u^{\prime} \frac{n}{\omega} \frac{d q^{b}}{d m}-c^{\prime}(q) \frac{n}{\omega} \frac{d q^{s}}{d m}=\frac{\gamma-\beta}{\beta} \frac{1}{\sigma_{b} A_{b}(T)}+1
$$

\footnotetext{
${ }^{26}$ Note that Rauch's formulation implies that the players' marginal values of money and their money holdings are observable. This is a critical assumption because agents might have an incentive to hide their money holdings in their backpockets in certain circumstances.

${ }^{27}$ Models with a nondegenerate distribution of money holdings are characterized by a decreasing marginal value of money. See for example Berentsen (2002), Camera and Corbea (1999), Rocheteau (2000), and Zhou (1999).

${ }^{28}$ Note that if $R_{m}^{s}=R_{m}^{b}=0$, the envelope condition is reduced to the one we have used so far in this paper. See Berentsen and Rocheteau (2001).
} 
Note that the right-hand side of (58) is equivalent to the right-hand side of the envelope condition we have used so far in this paper. If we assume that $\frac{d q^{b}}{d m}=\frac{\omega}{n} \frac{1}{c^{\prime}(q)}$ and $\frac{d q^{s}}{d m}=0$ and if we replace these two expressions in (58), we obtain the envelope condition we have used so far in this paper

$$
\frac{u^{\prime}}{c^{\prime}(q)}=\frac{\gamma-\beta}{\beta} \frac{1}{\sigma_{b} A_{b}(T)}+1
$$

We will refer to this specification of the envelope condition as the Shi specification because it has been proposed by Shi (1997).

Replacing $\frac{d q^{b}}{d m}$ and $\frac{d q^{s}}{d m}$ by using (53) and (55), respectively, the envelope condition (58) yields

$$
\frac{(1-2 \theta) \varepsilon c^{\prime}(q)\left[(1-\theta) c^{\prime}(q)+\theta u^{\prime}\right]+\left[(1-\theta) c^{\prime}(q)+\theta u^{\prime}\right]^{2}}{c^{\prime}(q)\left[(1-\theta) c^{\prime}(q)+\theta u^{\prime}\right]+\theta(1-\theta)[u(q)-c(q)] c^{\prime \prime}(q)}=\frac{\gamma-\beta}{\beta} \frac{1}{\sigma_{b} A_{b}(T)}+1
$$

We will refer to this specification of the envelope condition as the Rauch specification. Note that the hold-up effect is again represented by the second term in the numerator. The strategic effect is represented by the first term in the numerator. While the hold-up problem always depresses the value of money, the impact of the strategic effect depends on $\varepsilon$ and $\theta$. If the marginal value of money is decreasing and if $\theta<1 / 2$, the strategic effect depresses the value of money even further. In contrast if $\theta>1 / 2$, it has a positive impact on the equilibrium value of money. The problem is that we cannot say anything about the overall effect because we don't know how to derive $\varepsilon$. Consequently, we cannot simulate the optimal monetary policy as easily as would like to do. Nevertheless we can study the optimal monetary policy of several special cases as we do below.

Lagos and Wright (2002). In Lagos and Wright the elasticity of the marginal value of money is $\varepsilon=0$. Consequently, there is no strategic effect. This is so because of the special structure of their model, where agents can trade money in a centralized market at some exogenously given market price $\phi$. The main difference between the approaches of Lagos and Wright and Shi is that in Shi the pooling of money holdings is within households whereas in Lagos and Wright the pooling of money holdings is among all agents in the economy, which implies that in Shi the marginal value of money $\omega$ is household specific whereas in Lagos and Wright it is a market price. The models have in common that the pooling generates degenerate distributions of money holdings, which renders tractable models of fully divisible money.

If we set $\varepsilon=0$ in (60) we get

$$
\frac{\left[(1-\theta) c^{\prime}(q)+\theta u^{\prime}\right]^{2}}{c^{\prime}(q)\left[(1-\theta) c^{\prime}(q)+\theta u^{\prime}\right]+\theta(1-\theta)[u(q)-c(q)] c^{\prime \prime}(q)}=\frac{\gamma-\beta}{\beta} \frac{1}{\sigma_{b} A_{b}(T)}+1
$$

We will refer to this specification of the envelope condition as the Lagos-Wright specification. For this specification we can easily simulate the optimal monetary policy. In our simulations we have not found cases where it is optimal to deviate from the Friedman rule. Our simulations suggest 
the following reasons. First, the hold-up problem depresses the real stock of money so that under the Friedman rule $q<q^{*}$, unless the buyers have all the bargaining power. Consequently, in contrast to the Shi specification, a deviation from the Friedman rule has a negative first-order intensive effect. Second, an increase in the inflation rate no longer generates an increase in the search intensity of buyers because the surplus of the buyer $\left(\Theta(q)\left[u^{\prime} q-c(q)\right]\right)$ is an increasing function of $q$ for all $q \in\left(0, q^{f}\right)$ and it reaches a maximum at $q=q^{f}$, where $q^{f}$ is the quantity of goods produced and exchanged under the Friedman rule. As a consequence, the inflation tax also reduces the buyers search intensities. Thus, inflation has a negative intensive effect as well.

Symmetric bargaining. The case $\theta=1 / 2$ has been studied by Rauch (2000). This case is interesting because it also shuts off the strategic effect, i.e., the elasticity $\varepsilon$ vanishes in (60). Consequently, the results of our simulations are equivalent to the results obtained from simulating the Lagos-Wright specification for $\theta=1 / 2$.

Except for the special cases of symmetric bargaining and the Lagos-Wright specification, we are not able to simulate the Rauch approach. In particular, we cannot say anything of how the strategic effect would impact the optimal policy in Rauch's approach. For example, one interesting case would be buyer-takes-all bargaining $(\theta=1)$ because this case shuts off the hold-up effect but not the strategic effect. For this case, however, we know that if the marginal value of $\varepsilon$ is nonincreasing $(\varepsilon \leq 0)$, then in contrast to the Lagos-Wright specification for all $\gamma \geq \beta$, the quantity of goods traded will be larger or equal to the quantities traded in the Shi specification that we have used so far in this paper. The reason for this is that when $\theta=1$ the only active effect is the strategic effect, which reduces the quantities that the sellers have to produce in out-of-equilibrium matches, and consequently will increase the equilibrium value of money.

In summary, this section shows that the welfare implication of the model depends critically on the specification of the trading mechanism. Our approach and the approach by Rauch (2000) have in common that they involve trading mechanisms that generate allocations in the pairwise meetings that are incentive-feasible and pairwise Pareto efficient. That is, both approaches select allocations on the Pareto frontiers of the bargaining sets in all meetings. The main difference is that in our approach the buyers have the full bargaining power on their marginal unit of money, which involves different bargaining weights in equilibrium and in out-of-equilibrium matches. To the extend that choosing an allocation for a bilateral match involves always some arbitrariness, there is not a priori one trading mechanism more reasonable than another. Different trading mechanisms involve different protocols of bargaining (extensive forms) and the protocols might depend on the characteristics of the players, that is, there might be different protocols for equilibrium matches and out-of-equilibrium matches, where a player holds a different amount of money than what is expected in equilibrium. ${ }^{29}$ Another difference between the two approaches concerns

\footnotetext{
${ }^{29}$ Another paper that assumes different bargaining weights for a player depending on his characteristics, respec-
} 
welfare. In our approach the Friedman rule implements the first-best, while in the Rauch formulation because of the hold-up problem this is not the case. This suggest that in markets with the hold-up problem institutions might evolve such as competitive search that do not generate the hold-up inefficiency and where a deviation from the Friedman rule can be optimal as in our paper (see Rocheteau and Wright (2002)).

\section{Conclusion}

In this paper, we study the inefficiencies of the monetary equilibrium and optimal monetary policies in a search economy. We show that the same frictions that give fiat money a positive value generate two inefficiencies. One is an inefficient quantity of goods in each trade, due to the constrained real money balance, and the other is an inefficient number of trades, due to inefficient search decisions. The first inefficiency is common in all monetary models and the Friedman rule is required to eliminate it. The second inefficiency is unique to markets with decentralized exchanges and the Hosios (1990) rule is required to eliminate it. A monetary equilibrium attains the social optimum if and only if both rules are satisfied. This first best allocation cannot be attained when buyers' share in unconstrained bargaining $(\theta)$ is not equal to buyers' equilibrium share in the matching function under the Friedman rule, $\eta^{*}$. In this case, the second-best money growth rate obeys the Friedman rule when $\theta>\eta^{*}$ and exceeds the Friedman rule when $\theta<\eta^{*}$. We also show why the Hosios rule fails to internalize search externalities when barter is possible and how the rule can be modified in such an economy.

The second-best monetary policy exceeds the Friedman rule in the case $\theta<\eta^{*}$ because higher money growth can improve the efficiency of search decisions and hence the number of trades in this case. By increasing inflation, higher money growth reduces the real money balance and makes the trade more severely constrained by money. In this case, the buyer is able to extract a larger share of the match surplus than before, thus leading to an increase in the relative search intensity of buyers' to sellers'. This outcome improves the efficiency of search decisions when buyers' search intensity relative to sellers' is deficient under the Friedman rule, i.e., if $\theta<\eta^{*}$. Even in this case, the second-best money growth rate does not completely internalize the search externalities, as the Hosios rule requires, because that would require too large a reduction in the real money balance, and hence would exacerbate the inefficiency in the quantity of goods in each trade by too much, to be optimal.

We want to emphasize that the two inefficiencies arise from the same frictions that support the value of fiat money. So, the welfare property of the Friedman rule, whether that being optimal or sub-optimal, is inseparable from valued money. This feature of our model provides a defense against the usual criticism that the presence of too many frictions and too few policy instruments tively, the type of match he is in, is Ravikumar and Wallace (2003). 
is the cause of the sub-optimality of the Friedman rule. To clarify this issue, consider the case $\theta<\eta^{*}$, where buyers' search intensity relative to sellers' is deficient if money growth obeys the Friedman rule. In this case, a lump-sum transfer from sellers to buyers can help internalize the search externalities and restore the Friedman rule as the optimal monetary policy. However, if such lump-sum transfers were unconstrained, then there would be no need for fiat money in the described environment: The social planner could achieve the social optimum by making the transfer as large as the seller's entire output in every match with a single coincidence of wants. Thus, to examine additional policies in a meaningful way, these policies must not replace fiat money in the exchange and hence must be costly to implement. We plan to examine in a sequel some of these costly policies, such as distortionary taxes. 


\section{References}

[1] Berentsen, Aleksander (2002), On the Distribution of Money Holdings in a Random-Matching Model, International Economic Review, Vol. 43, No. 3, 945-954.

[2] Berentsen, Aleksander and Guillaume Rocheteau (2003). Money and the Gains from Trade. International Economic Review, Vol. 44, No. 1, February 2003 (in print).

[3] — (2002). On the Efficiency of Monetary Exchange: How Divisibility of Money Matters. Journal of Monetary Economics, 49:8, November 2002, 1621-49.

[4] — (2001). A Note on the Friedman Rule in Search Models with Divisible Money. Manuscript, University of Basel.

[5] Bewley, Truman (1980). The Optimum Quantity of Money: A Formal Treatment. In: Kareken, John H. and Neil Wallace (ed.) Models of Monetary Economies (pp.169-210). Federal Reserve Bank of Minneapolis, Minneapolis.

[6] Camera, Gabriele and Dean Corbae (1999), "Money and Price Dispersion," International Economic Review 40, 985-1008.

[7] Chamley, Christophe (1985). On a Simple Rule for the Optimal Inflation Rate in Second Best Taxation. Journal of Public Economics 26, 35-50.

[8] Chari, V.V., Christiano, Lawrence J. and Patrick J. Kehoe (1991). Optimal Fiscal Policy and Monetary Policy: Some Recent Results. Journal of Money, Credit, and Banking 23, 519-539.

[9] Deviatov, Alexei and Neil Wallace (2001). Another Example in which Lump-Sum Money Creation is Beneficial. Advances in Macroeconomics 1 (no.1), 1-20.

[10] Diamond, Peter (1982). Wage Determination and Efficiency in Search Equilibrium, Review of Economic Studies 49, 217-227.

[11] Engineer, Merwan and Shouyong Shi (1998). Asymmetry, Imperfectly Transferable Utility, and the Role of Fiat Money in Improving Terms of Trade. Journal of Monetary Economics $41,153-183$.

[12] — (2001). Bargains, Barter, and Money. Review of Economic Dynamics 4, 188-209.

[13] Faig, Miquel (2001). A Search Theory of Money and Commerce with Neoclassical Production. Manuscript, University of Toronto.

[14] Friedman, Milton (1969). The Optimum Quantity of Money. In: The Optimum Quantity of Money and Other Essays, Aldine, Chicago, 1-50.

[15] Green, Edward and Ruilin Zhou (1998). A Rudimentary Model of Search with Divisible Money and Prices. Journal of Economic Theory 81, 252-271.

[16] Head, Allen and Shouyong Shi (2000). A Fundamental Theory of Exchange Rates and Direct Currency Trades. Manuscript, Indiana University. 
[17] Hosios, Arthur J. (1990). On the Efficiency of Matching and Related Models of Search and Unemployment. Review of Economic Studies 57, 279-298.

[18] Kiyotaki, Nobuhiro and Randall Wright (1991). A Contribution to the Pure Theory of Money. Journal of Economic Theory 53, 215-235.

[19] (1993). A Search-Theoretic Approach to Monetary Economics. American Economic Review 83, 63-77.

[20] Kocherlakota, Narayana (1998). Money is Memory, Journal of Economic Theory 81, 232-251.

[21] Lagos, Ricardo and Randall Wright (2002). A Unified Framework for Monetary Theory and Policy Analysis. Manuscript, University of Pennsylvania.

[22] Levine, David (1991). Asset Trading Mechanisms and Expansionary Policy, Journal of Economic Theory 54, 148-164.

[23] Li, Victor (1995). The Optimal Taxation of Fiat Money in Search Equilibrium. International Economic Review 36, 927-942.

[24] — (1997). The Efficiency of Monetary Exchange in Search Equilibrium. Journal of Money, Credit and Banking 29, 61-72.

[25] Lucas, Robert E. (1990). Liquidity and Interest Rates. Journal of Economic Theory 50, 237264.

[26] Moen, Espen R. (1997). Competitive Search Equilibrium. Journal of Political Economy 105, $385-411$.

[27] Molico, Miguel (1997). The Distribution of Money and Prices in Search Equilibrium. Ph.D. dissertation, University of Pennsylvania.

[28] Mortensen, Dale (1982). Property Rights and Efficiency in Mating, Racing, and Related Games. The American Economic Review 72, 968-979.

[29] Osborne, Martin and Ariel Rubinstein (1990). Bargaining and markets. Academic Press, San Diego.

[30] Pissarides, Christopher A. (1990). Equilibrium Unemployment Theory. Basil Blackwell, Cambridge, Massachusetts.

[31] Rauch, Bernhard (2000). A Divisible Search Model of Fiat Money: A Comment. Econometrica $68,149-156$.

[32] Ravikumar, B and Neil Wallace (2002). A Benefit of Uniform Currency, Mimeo, Department of Economics, Pennsylvania State University.

[33] Rocheteau, Guillaume (2000), La Quantité Optimale de Monnaie dans un Modèle avec Appariements Aléatoires, Les Annales d'Economie et Statistique 58, 101-142.

[34] Rocheteau, Guillaume and Randall Wright (2002), Money in Search Equilibrium, in Competitive Equilibrium, and in Competitive Search Equilibrium. Unpublished manuscript, University of Pennsylvania. 
[35] Schmitt-Grohe, Stephanie and Martin Uribe (2000). Optimal Fiscal and Monetary Policy Under Imperfect Competition. Manuscript, University of Pennsylvania.

[36] Shi, Shouyong (1995). Money and Prices: A Model of Search and Bargaining. Journal of Economic Theory 67, 467-496.

[37] — (1997). A Divisible Search Model of Fiat Money. Econometrica 65, 75-102.

[38] — (1998). Search for a Monetary Propagation Mechanism. Journal of Economic Theory $81,314-352$.

[39] (1999a). Search, Inflation and Capital Accumulation. Journal of Monetary Economics 44, 81-103.

[40] - (1999b). Money, Capital, and Redistributive Effects of Monetary Policies. Journal of Economic Dynamics and Control 23, 565-590.

[41] (2001a). Liquidity, Bargaining, and Multiple Equilibria in a Search Monetary Model. Annals of Economics and Finance 2, 325-351.

[42] — (2001b). Frictional Assignment. I. Efficiency. Journal of Economic Theory 98, 232-260.

[43] Townsend, Robert M. (1980). Models of Money with Spatially Separation. In: Kareken, John H. and Neil Wallace (ed.) Models of Monetary Economies (pp.265-303). Federal Reserve Bank of Minneapolis, Minneapolis.

[44] Trejos, Alberto and Randall Wright (1995). Search, Bargaining, Money and Prices. Journal of Political Economy 103, 118-141.

[45] Wallace, Neil (2001). Whither Monetary Economics. International Economic Review 42, 847869.

[46] Williamson, Stephen D. (1996). Sequential Markets and the Suboptimality of the Friedman Rule. Journal of Monetary Economics 37, 549-572.

[47] Woodford, Michael (1990). The Optimum Quantity of Money. In: Friedman, Benjamin M. and Frank H. Hahn (eds.) Handbook of Monetary Economics, vol. II. Elsevier Science Publisher B.V., Amsterdam.

[48] Zhou, Ruilin (1999), Individual and Aggregate Real Money Balances in a Random-Matching Model, International Economic Review 40, 1009-1038. 


\section{Appendix}

\section{A Proofs of Propositions 2 and 4}

We prove Proposition 2 first. Dividing (29) by (30), substituting $\Theta$ from (27) and using $\phi(\sigma)=$ $\phi_{0}\left(\sigma^{\alpha}-1\right)$, we have:

$$
q=g(T) \equiv c^{\prime-1}\left(\left(T / T^{*}\right)^{\alpha} u^{\prime}\right),
$$

where $T^{*}$ is defined in (32). Note that $g^{\prime}(T)>0$. Solve $\sigma_{b}$ as a function of $q$ from (31). Substitute this for $\sigma_{b}$ and $g(T)$ for $q$ into (29). Then, the equilibrium tightness is the solution to $G(T)=(\gamma / \beta-1)^{\alpha-1}$, where

$$
G(T)=\left[\left(T^{*}\right)^{\alpha}-T^{\alpha}\right]^{\alpha-1} \frac{\left[T^{1-\alpha} A_{b}(T)\right]^{\alpha}[u(g(T))-c(g(T))]}{\alpha \phi_{0}\left[1+\left(\frac{n}{1-n}\right)^{\alpha-1} T^{\alpha}\right]} .
$$

We show that there exists a positive solution for $T$ to the above equation. Because the equilibrium must satisfy $q \leq q^{*}$, which requires $T \leq g^{-1}\left(q^{*}\right)=T^{*}$, the proper domain of $T$ is $\left[0, T^{*}\right]$. For $T \in\left[0, T^{*}\right], G(T)$ is continuous and differentiable. Note that $G\left(T^{*}\right)=0 \leq$ $(\gamma / \beta-1)^{\alpha-1}$ for all $\gamma \geq \beta$. For there to be a solution for $T$ in $\left[0, T^{*}\right]$, it is necessary and sufficient that $G(T) \geq(\gamma / \beta-1)^{\alpha-1}$ for some $T \in\left[0, T^{*}\right]$, i.e., if and only if $\gamma \leq \gamma_{\max }$ where

$$
\gamma_{\max } \equiv \beta\left[1+\left(\max _{T \in\left[0, T^{*}\right]} G(T)\right)^{1 /(\alpha-1)}\right] .
$$

Because $G(T)$ is continuous and the domain $\left[0, T^{*}\right]$ is a closed interval, $\gamma_{\max }$ is well-defined. Moreover, since $G\left(T^{*}\right)=0$ and $\lim _{T \uparrow T^{*}} \frac{G^{\prime}\left(T^{*}\right)}{G\left(T^{*}\right)}=-\infty$, we have $G(T)>0$ for $T$ sufficiently close to but smaller than $T^{*}$. Thus, $\gamma_{\max }>\beta$. If $G(T)$ is maximized at $T=0$, then re-label $\gamma_{\max }-\varepsilon$ as $\gamma_{\max }$, where $\varepsilon>0$ is arbitrarily small, to ensure that the solution for $T$ is positive at $\gamma=\gamma_{\max }$. Therefore, the monetary equilibrium exists iff $\gamma \in\left[\beta, \gamma_{\max }\right]$.

The solution for $T$ may not be unique. We focus on the solution that implies $q \rightarrow q^{*}$ when $\gamma \rightarrow \beta$, i.e., $T \rightarrow T^{*}$ when $\gamma \rightarrow \beta$. Only the largest solution for $T$ has such a property. Because $G(T)$ exceeds $(\gamma / \beta-1)^{\alpha-1}$ for some $T \in\left(0, T^{*}\right)$ and falls below $(\gamma / \beta-1)^{\alpha-1}$ at $T=T^{*}$, the largest solution for $T$ satisfies $G^{\prime}(T)<0$. This solution must then have the property $d T / d \gamma<0$. With this, (62) implies $d q / d \gamma<0$. The definition of $T$ implies $\sigma_{b} / \sigma_{s}=(1-n) /(n T)$. Since $d T / d \gamma<0$, we have $d\left(\frac{\sigma_{b}}{\sigma_{s}}\right) / d \gamma>0$. This completes the proof of Proposition 2.

For Proposition 4, consider first the case $\eta\left(T^{*}\right)>\theta$ and examine $\mathcal{W}^{\prime}(\gamma)$ in (35). If $\gamma$ is set at $\beta$, then $u^{\prime}=c^{\prime}, T=T^{*}$ and $\Theta=\theta$. The first term of $\mathcal{W}^{\prime}(\beta)$ is zero and the second term is positive, implying $\mathcal{W}^{\prime}(\beta)>0$. Thus, the second-best money growth rate exceeds the Friedman rule. Similarly, if $\gamma$ is set to $\gamma^{h}$, then $u^{\prime}<c^{\prime}, T=T^{h}$ and $\eta\left(T^{h}\right)=\Theta\left(q^{h}\right)$, implying $\mathcal{W}^{\prime}\left(\gamma^{h}\right)<0$. Thus, the second-best money growth rate is lower than $\gamma^{h}$.

Now consider the case $\eta\left(T^{*}\right)<\theta$. We show that $\eta(T)<\Theta(q)$ in this case for all $\gamma \geq \beta$. Then, the second term of $\mathcal{W}^{\prime}(\gamma)$ is negative and $\mathcal{W}^{\prime}(\gamma)<0$ for all $\gamma \geq \beta$, implying that optimal money growth is $\gamma=\beta$. Consider the function $F(T) \equiv T[\eta(T)-\Theta(g(T))]$, where $g(T)$ is defined in (62) and has the property $g^{\prime}(T)>0$. Clearly, $\eta(T)<\Theta(g(T))$ iff $F(T)<0$. Using (8) to substitute $\eta(T)$, it can be shown that there exists a unique $T_{1}$ such that $F(T)<0$ is equivalent to $T<T_{1}$. Since $F\left(T^{h}\right)=0, T_{1}=T^{h}$. Because $d T / d \gamma<0$, we have $F(T)<0$ iff $\gamma>\gamma^{h}$. Because $F\left(T^{*}\right)<0$ 
in the current case (i.e., $\eta\left(T^{*}\right)<\theta$ ) and $T=T^{*}$ when $\gamma=\beta$, we have $\beta>\gamma^{h}$. Thus, $F(T)<0$ for all $\gamma \geq \beta$ in this case, as desired.

Finally, we show that $\eta\left(T^{*}\right)>\theta$ iff $\eta\left(T^{h}\right)>\theta$. $>$ From the definition of $T^{*}$ in (32) and of $T^{h}$ in footnote 17 , we have $J 1\left(T^{*}\right)=0$ and $J 2\left(T^{h}\right)=0$, where

$$
\begin{gathered}
J 1(T) \equiv T^{\alpha-1}-\left(\frac{1-n}{n}\right)^{\alpha-1}\left(\frac{1}{\theta}-1\right) \frac{1}{T}, \\
J 2(T) \equiv T^{\alpha-1}-\left(\frac{1-n}{n}\right)^{\alpha-1}\left(\frac{1}{\eta(T)}-1\right) \frac{1}{T} .
\end{gathered}
$$

The functions $J 1($.$) and J 2($.$) are strictly increasing (recall that \frac{1}{T}\left(\frac{1}{\eta(T)}-1\right)=f(T)$ is a decreasing function of $T)$. Also, for any $T>0, J 1(T)>J 2(T)$ if and only if $\eta(T)>\theta$. Consider the case $\eta\left(T^{h}\right)>\theta$. In this case, $J 1\left(T^{h}\right)>J 2\left(T^{h}\right)=0$. Because $J 1^{\prime}(T)>0$ and $J 1\left(T^{*}\right)=0$, the result $J 1\left(T^{h}\right)>0$ implies $T^{*}<T^{h}$. The property $J 2^{\prime}(T)>0$ then implies $J 2\left(T^{*}\right)<J 2\left(T^{h}\right)=0=J 1\left(T^{*}\right)$. Because $J 1(T)>J 2(T)$ in the current case iff $\eta(T)>\theta$, the result $J 1\left(T^{*}\right)>J 2\left(T^{*}\right)$ implies $\eta\left(T^{*}\right)>\theta$. That is, $\eta\left(T^{h}\right)>\theta$ implies $\eta\left(T^{*}\right)>\theta$. Similarly, $\eta\left(T^{h}\right)<\theta$ implies $\eta\left(T^{*}\right)<\theta$. Therefore, $\eta\left(T^{*}\right)>\theta$ iff $\eta\left(T^{h}\right)>\theta$. QED 